\title{
A Fuzzy Programming Model for Positioning Customer Order Decoupling Point Based on QFD in Logistics Service with Mass Customization
}

\author{
Guanxiong Wang ${ }^{1}$ and Xiaojian $\mathrm{Hu}$ iD $^{2,3}$ \\ ${ }^{1}$ School of Business, Anhui University, Hefei, China \\ ${ }^{2}$ School of Management, Hefei University of Technology, Hefei, China \\ ${ }^{3}$ Key Laboratory of Process Optimization and Intelligent Decision-Making, Ministry of Education, Hefei, China
}

Correspondence should be addressed to Guanxiong Wang; 767747816@qq.com

Received 23 July 2020; Revised 20 October 2020; Accepted 21 October 2020; Published 6 November 2020

Academic Editor: Wangyan Li

Copyright $\odot 2020$ Guanxiong Wang and Xiaojian Hu. This is an open access article distributed under the Creative Commons Attribution License, which permits unrestricted use, distribution, and reproduction in any medium, provided the original work is properly cited.

\begin{abstract}
Mass customization logistics service mode provides a new way to maintain the sustainable cooperative relationship between customers and integrators. One of the key factors to maintain the sustainable development of logistics service supply chain under MC mode is to locate a suitable customer order decoupling point (CODP) location. This paper investigates the problem of CODP in the logistics service supply chain based on the fuzzy set theory under the mass customization mode. With the help of a fuzzy QFD method and a new service quality function that we constructed, this paper quantifies the quality of a logistics service when the LSI selects a different CODP. Then, the fuzzy set of the high-quality logistics service and the fuzzy set of the satisfactory delivery time are built. Based on those two new fuzzy sets, this paper builds a new fuzzy programming model on CODP positioning. The solving methods of this model under different conditions are given. Finally, the influence of some important parameters on the optimal CODP position is studied by sensitivity analysis on a specific numerical case.
\end{abstract}

\section{Introduction}

Against the background of steadily growing transport volumes and increasingly fierce market competition, it is of paramount importance for the logistics service integrators (LSI) to provide customers with customized services to meet the diverse needs of the market and maintain sustainable partnership with customers. Based on this, more and more logistics enterprises are making use of the scale effect as much as possible to reduce the total logistics cost while providing customized services. In other words, those logistics enterprises try to implement mass customization (MC) in the logistics service supply chain $[1,2]$. MC can be seen as a collaborative optimization process between a company and its customers with the goal of finding the best match between the company's capabilities and the customers' needs [3-5].
Compared with other types of service industries, there are some unique characteristics in the logistics service industry. At first, the degree of the customer's participation is not high in the process of providing logistics services. After the order is submitted, the customer only needs to wait for the order to complete, without the need for full participation in the logistics service process, which means that the fluctuation of the service requirement is low. Second, general service emphasizes the immediacy of service provision; however, customers have relaxed their requirements for time in the process of providing logistics service. Customers often set a time constraint and require logistics enterprises to fulfill orders within this time limit. For the abovementioned reasons, implementing mass customization in the logistics service supply chain is flexible.

An important issue of mass customization is locating the customer order decoupling point (CODP) [6-9]. In the 
logistics service supply chain, CODP is the boundary between mass logistics services and customized logistics services [10]. Different CODP locations will not only affect the benefits of LSI but also affect the service quality of the whole logistics service supply chain. Therefore, evaluating the service quality level of logistics service supply chain with different CODP locations will help LSI to improve the logistics service process sustainably and provide customers with better service.

Regarding a mass customization logistics service, customer enterprises outsource their logistics tasks to LSIs. LSIs analyze the characteristics and the customized requirements of those logistics tasks after the orders arrived; then, they disassemble the logistics process into many specific service procedures according to the actual situation. Finally, by collaborating with functional logistics service providers (denoted as FLSPs), they provide mass service for that shared service part and customized logistics service for the subsequent processes that have special requirements. Thus, it is imperative to consider the effects of the position of the CODP both on the comprehensive performance of the LSI logistics service and the promotion of customer satisfaction $[7,9,11]$.

For logistics service integrators, the goal is to maximize profits with a precondition of satisfying the customers' requirements $[12,13]$. Different from providing standardized services, LSIs provide customized and variant service in the MC environment. Therefore, an LSI can charge different prices for logistics services according to the degree of customization, so as to maximize profits.

For customer enterprises, what they value most is logistics service quality (denoted as LSQ) [14-16]. Since there is no uniform standard to measure service quality, most of the current studies evaluate logistics service quality through qualitative research [17]. Many of those studies include lead time in the service evaluation system as an important quantitative index together with other qualitative indicators $[18,19]$. Most studies considered that the sooner the LSI completes the logistics orders, the more satisfied the customer is. In reality, however, customer enterprises want lead time to be close to their preset time rather than the shortest delivery time, since the product recipient (for instance, terminal retailers) will increase inventory costs if the LSI delivers goods too early, and if the LSI delivers goods too late, it will affect the recipient's sale, inventory, and replenishment.

Based on a review of the literature and the analysis of practical problems related to logistics enterprises, we found that there are three problems that should be solved for the LSI in the mass customization circumstance. (1) How to measure logistics service quality: because there is no uniform standard to measure the logistics service quality, and the quality of service is difficult to quantify. Therefore, it is a complex problem to translate this type of indicators into specific constraint conditions in a programming model. (2) How to describe the uncertainty of the customers' service requirements: as mentioned above, the customers' requirements for service quality and lead time are indeterminate, how to reflect those uncertainties in mathematical model is another problem. In the previous research, customer requirements were regarded as deterministic and the variability and volatility of customer requirements were ignored. Therefore, most of the constraints on the optimized model for CODP positioning are deterministic [20-22]. (3) Pricing strategy of differentiated services: since the logistics services provided by the LSI are customized and differentiated, the costs and delivery time will be different due to the different degrees of customization. Therefore, an urgent problem for LSIs is how to price for differentiated services.

The problems mentioned above will be discussed in this paper and a fuzzy programming model for positioning CODP is developed. This paper combines quantitative analysis and qualitative analysis to measure customer satisfaction using qualitative indicators and quantitative indicators, and our contributions in this paper are as follows.

First, based on the fuzzy theory, this paper constructs two new fuzzy sets: the fuzzy set of high-quality logistics service and the fuzzy set of satisfactory delivery time. Then, based on those two fuzzy sets, a new fuzzy programming model on CODP positioning with fuzzy constraints is developed and introduced in this paper. Compared with deterministic constraints, fuzzy constraint sets can reflect the customer's demands more completely and more accurately. In this paper, the research on CODP position is extended from deterministic programming to fuzzy programming, which provides more ideas and methods for researchers or business decision makers.

Second, the fuzzy Quality Function Deployment method is used to characterize the logistics service quality under different CODP conditions as a specific score, and by using the logistics service quality function constructed in this paper, the score is expressed as a more intuitive result so that the decision maker can more clearly see the difference in service quality when choosing different CODPs. This method comprehensively considers the impact of various qualitative indicators on logistics service quality, so it can improve logistics service quality sustainably according to this method.

Third, through numerical case analysis, this paper discusses which parameters have a significant impact on the location of the CODP, to provide managers with effective management insights, improve logistics enterprise operation efficiency, and reduce logistics costs.

The rest of the paper is organized as follows. In Section 2, we review and summarize the research status of mass customization in service field and the research progress of CODP positioning. In Section 3, the conditional assumptions and the mathematical expression of this model are presented. In Section 4, the quantify methods of some important indicators are given in Section 4.1; then, we build a fuzzy programming model with two fuzzy constraints and provide methods to solve the model. In Section 5, the feasibility of the model is verified through a numerical example, and a sensitivity analysis is performed for the parameters of the model to evaluate the effect of those parameters on the results. In Section 6, we summarize the research process and the significance of this study and provide some important implications for management and a possible future research direction. 


\section{Literature Review}

2.1. MC in the Service Industry. Mass customization mode originated from manufacturing industry [23]. Due to the heterogeneity and invisibility of services and the volatility of service demand, there are relatively few research studies on the implementation of mass customization mode in service industry. In the early stage, scholars and practitioners began to explore the possibility of implementing mass customization in service industry [3], for example, Moon et al. developed a method to design customized service families using game theory to simulate situations involving dynamic market environments [24]; Wang focused on service mass customization, analyzed the shortcomings of traditional SaaS and service composition methods, and proposed "service network" as a means to solve the contradiction between "large-scale standardization" and "personalization" [25].

At present, the research on mass customization mode of service industry can be roughly divided into two categories. The first one is about the concept, strategic thinking, and key elements of implementing mass customization mode in service industry, for instance, Peters et al. summarized the challenges of implementing mass customization in service environment and proposed the driving factors for enterprises to implement service mass customization mode [26]. The second kind of research mainly focuses on the specific operation problems of mass customization in the service supply chain, such as the joint optimization of supplier selection and order allocation [27] and optimal customization degree or CODP positioning under the mode of logistics service mass customization [21].

As can be seen from the literature review above, although mass customization has received increasing attention, the research and application of MC in the service industry is still relatively scarce; at present, only a small number of service industries have successfully implemented a mass customization service mode.

2.2. CODP Position. One of the key problems in mass customization production or service mode is to determine the optimal customer order decoupling point $[11,28]$. Mass customization mode originated from the field of manufacturing, so the research on CODP is mostly focused on manufacturing industry [6], for instance, Jeong et al. proposed a dynamic model to simultaneously determine the optimal location of decoupling points and production inventory planning in the supply chain, so as to minimize the total cost of deviation from target productivity and target inventory level [29]. Schoenwitz proposed a systematic approach to determine the alignment of CODP configurations at product, category, and component levels, with customer preferences in terms of their customization requirements [30].

The research on CODP positioning can be divided into single CODP positioning research and multiple CODP positioning research. Research on single CODP, for instance, de Keizer et al. proposed a network design model for perishable products that integrates decision-making on hub locations with the positioning of the CODP and the determination of the level of postponement [31]; Liu et al. proposed the optimal decision model of customer of CODP for order insertion scheduling in the logistics service supply chain [13], research on multiple CODP, for instance. In order to adapt to the dynamic environment, Wang and Chen proposed a multi-CODP positioning and adjustment system [21]. Shidpour et al. studied the impact of single CODP and multiple CODPs on product diversity based on enterprise profit and customer perceived value under service time constraint [32]; Cannas et al. assessed the potential impact of a unique two-dimensional customer order decoupling point framework and evaluated the managerial approaches employed in different decoupling configurations [33].

With the development of the service supply chain, more and more scholars begin to pay attention to the positioning of CODP in the service supply chain. For example, Wang et al. proposed a joint optimization model considering both order allocation and CODP positioning under the mode of mass customization of logistics services [28]. Guo et al. proposed a Formulation-Exploration method to make decisions on CODP positioning and improve the supply chain to support mass customization [34]. Liu proposed a determination method of optimal customization degree of the logistics service supply chain with mass customization service [35].

From the above literature review, it is not difficult to find that there are few research studies on the positioning of CODP in the service industry, and the positioning methods of CODP are mostly quantitative or qualitative. However, the research on the combination of quantitative research and qualitative research to determine the optimal CODP location is still rare.

\section{Model Description and Model Assumptions}

After receiving orders from product demanders, customer enterprises outsource their logistics tasks (including transportation, labelling, assembly, and distribution) to the LSI. The first step for the LSI is to analyze the features of this logistics order and the customized requirements of the customer enterprises, break down complex tasks into $N$ sequential subprocedures, and then assign those subprocedures to the appropriate FLSPs. In other words, the entire logistics task will be completed by the LSI and many FLSPs. The LSIs will price logistics service according to the degree of customization compared with standardized service. The customer enterprises not only propose customized requirements but also set high requirements for service flexibility and reliability, i.e., the higher the logistics service quality is, the more satisfied the customers are. In addition, customer enterprises desire a lead time close to the time interval that they preset instead of the shortest delivery time.

Our aim is to find an optimal CODP (the position of the CODP is denoted by $k=i$ or $k_{i}$ ), all of the subprocedures before the CODP will implement a mass service strategy, and the subprocedures after the CODP will implement a customized service strategy according to the customer's 
requirements; thus, the LSI will maximize profits as well as meet customers' requirements under this mixed strategy. The logistics service supply chain structure under the mass customization environment is shown in Figure 1.

To develop a model that is tractable, we shall assume that as follows. The parameters for our model and their description are shown in Table 1.

Assumption 1. Considering the scale effect, we assume that the unit cost of every subprocedure could be denoted by $\left.\left(1-\lambda \cdot t c_{i} n, q \lambda h \in_{[} 0,1\right)\right)$, and the scale effect coefficient is bigger than 0 but no more than 1 in the mass service mode, and the scale effect coefficient is equal to zero in the customized service mode.

Assumption 2. Considering the scale effect, we assume that the unit time of every subprocedure could be denoted by $(1-\lambda)^{-1} \cdot c_{i}, \lambda \in[0,1)$, where the scale effect coefficient is bigger than 0 but no more than 1 in the mass service mode, and the scale effect coefficient is equal to zero in the customized service mode.

Assumption 3. Assuming that the LSI provides two types of products, i.e., standardized service products and customized service products, the price of the former is constant, and the price of customized service will increase with greater the degree of customization.

Assumption 4. We assume that the degree of customization is described by the position of the CODP. The degree of customization will decrease with the movement of CODP from upstream of the supply chain to the downstream. We further assume that the degree of customization is equal to 1 when the CODP is located at the first subprocedure, and the degree of customization is equal to 0 when the CODP is located at the last subprocedure.

Assumption 1 means that, for the same subprocedures, the unit cost of a subprocedure in the mass service mode is lower than their unit cost in the customized mode. Assumption 2 means that, for the same subroutine, the unit time spent in the mass service model is more than the unit time spent in the customized service model. In other words, the service time is inversely associated with the service scales.

\section{Model Building and Solving}

In Section 4.1.1, we quantify the important indicators in the model: the operation cost indexes and operation time indexes; in Section 4.1.2, we determine the qualitative indicators of logistics service quality evaluation and then use the method of Fuzzy QFD to quantify these qualitative indicators, which lays the foundation for the constraints of the next step of the fuzzy programming model.

In Section 4.2, the objective function of the model is constructed, and two fuzzy constraint sets are built: the highquality logistics service fuzzy set and the satisfactory delivery time fuzzy set; then, on the basis of the objective function and the fuzzy constrains, a fuzzy programming model for
CODP location in the LSSC is built. In Section 4.3, we provide the solution method and the process for solving the model under different conditions. The overall proposed procedure for positioning CODP is illustrated in Figure 2.

\subsection{Quantitative Index}

4.1.1. Quantitative Cost Index and Time Index. As mentioned earlier, the subprocedures before $k$ (including the $k$ subprocedure) are implemented in the mass service mode, and the subsequent subprocedures are implemented in the customized mode, which means the total cost of the logistics service consists of two parts: the cost of mass service and the cost of customized service. According to Assumption 1, the total cost of mass service is $\sum_{i=1}^{k}(1-\lambda) \cdot c_{i} \cdot \mu$, the total cost of customized service is $\sum_{i=k+1}^{N} c_{i} \cdot \mu$. Therefore, the total cost can be expressed as follows:

$$
C(k)=\sum_{i=1}^{k}(1-\lambda) \cdot c_{i} \cdot \mu+\sum_{i=k+1}^{N} c_{i} \cdot \mu .
$$

Similarly, the total time of all logistics services also consist of two parts: the mass service time and the customized service time. According to Assumption 2, the total time of the mass service portion can be calculated as $\sum_{i=1}^{k}(1-\lambda)^{-1} \cdot t_{i}$. On the contrary, the scale effect has no impact on the time of the customized service, i.e., $\lambda=0$. Therefore, the total time of the entire logistics service can be expressed as follows:

$$
T(k)=\sum_{i=1}^{k}(1-\lambda)^{-1} \cdot t_{i}+\sum_{i=k+1}^{N} t_{i} .
$$

Another important time index is the lead time, and we use an interval number $T=\left[T_{s}, T_{l}\right]$ to indicate the shortest and longest lead time of a service order that can be accepted by the customers. We use $T_{E}=1 / 2\left(T_{s}+T_{l}\right)$ to refer to the customer's expected lead time, so the LSI lead time should be closest to $T_{E}$.

\subsubsection{Quantitative Service Quality Index Using a Fuzzy} Quality Function Deployment (Fuzzy QFD) Approach. Compared with the quantitative cost index and time index, it is more complex to quantify service quality. We utilize the Quality Function Deployment approach [11, 36-38] to analyze our problems. In this section, we use a mixed method and deliver qualitative insights based on semistructured interviews and quantitative insights based on fuzzy QFD. The evaluation information is obtained by means of field visits and semistructured interviews with both logistics experts and customers, and then the information will be processed and filled into the house of quality (HOQ). According to the following algorithm, we first determine the ability factor and the quality factor and then calculate the influence degree of the capability factor on the quality factor. Then, combining the evaluation information about the logistics service ability when the LSI selects different CODPs, we calculate the scores of the logistics service quality. Finally, 


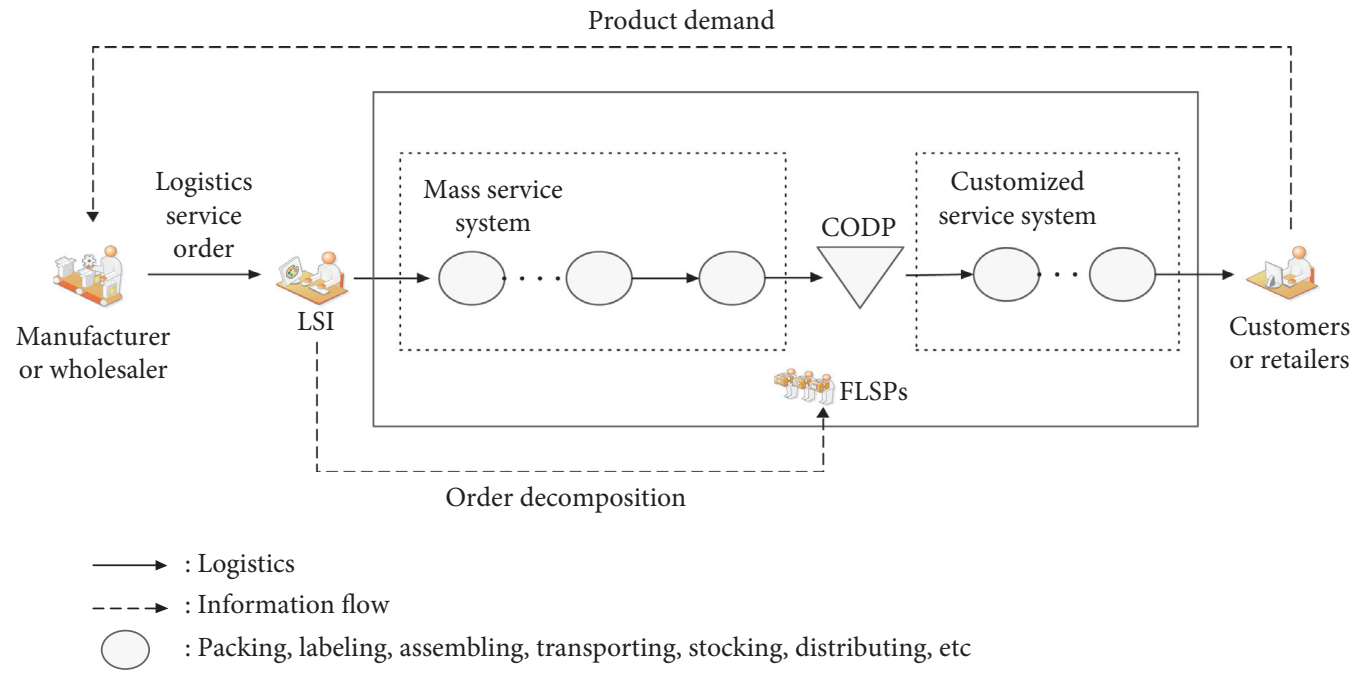

FIGURE 1: The logistics service supply chain structure under the mass customization environment.

TABLE 1: Parameters for the CODP position model.

\begin{tabular}{lc}
\hline Notations & Description \\
\hline$G(k)$ & Gross profit when the CODP is $k$ \\
$P(k)$ & Service price when the LSI sets the CODP at $k$ \\
$P_{s}$ & Price of standardized service products \\
$C(k)$ & Total cost of order processing when the CODP is $k$ \\
$c_{i}$ & Unit cost of logistics service in the $i$ th procedure \\
$T(k)$ & Delivery time, i.e., total service time when the CODP is $k$ \\
$t_{i}$ & Operation time of logistics service in the $i$ th procedure \\
$Q(k)$ & Service quality when the CODP is $k$ \\
$T_{s}, T_{l}$ & The shortest and longest lead time of service orders that customers will accept, respectively \\
$\lambda$ & Scale effect coefficient \\
$\mu$ & Amount of logistics service \\
$i$ & Serial number of subprocedures \\
$k_{i}$ & CODP locates at the $i$ th subprocedure \\
$k$ & The position of the CODP, $k=1, \ldots$, i, $\ldots$, when, $i \leq k$, the $i$ th subprocedure implements mass service; when $i>k, i$ th \\
$k^{*}$ & subprocedure implements customized service \\
$N$ & The optimal position of the CODP \\
$\alpha$ & Total number of procedures \\
$1-\alpha$ & Weight of logistics service quality \\
$\beta$ & Weight of time index \\
$1-\beta$ & Weight of objective function \\
\hline
\end{tabular}

these scores are entered into the logistics service quality function constructed by this paper; thus, a more intuitive and more acceptable result is obtained.

Based on the intensive study of the related theory and previous work, we know that evaluating service quality is a continuous process, which can be summarized in the following steps:

(i) Identify the quality factors of the logistics service proposed by customers: "WHATs"

(ii) Assess and calculate the importance of every service quality factor

(iii) Identify logistics service ability factors that affect service quality: "HOWs" (iv) Determine the relationship between the service quality factors and the service ability factors

(v) Determine the influencing degree of every ability factors on the overall service quality by matrix calculation

(vi) Evaluate the performance of the LSI service when the LSI selects different CODPs

(vii) Determine the service quality by means of HOQ, and then we can utilize our service quality function to obtain a more intuitive result to describe the quality of the logistics service

By referring to a large number of related studies $[39,40]$, we summarize the information on indexes into Table 2 


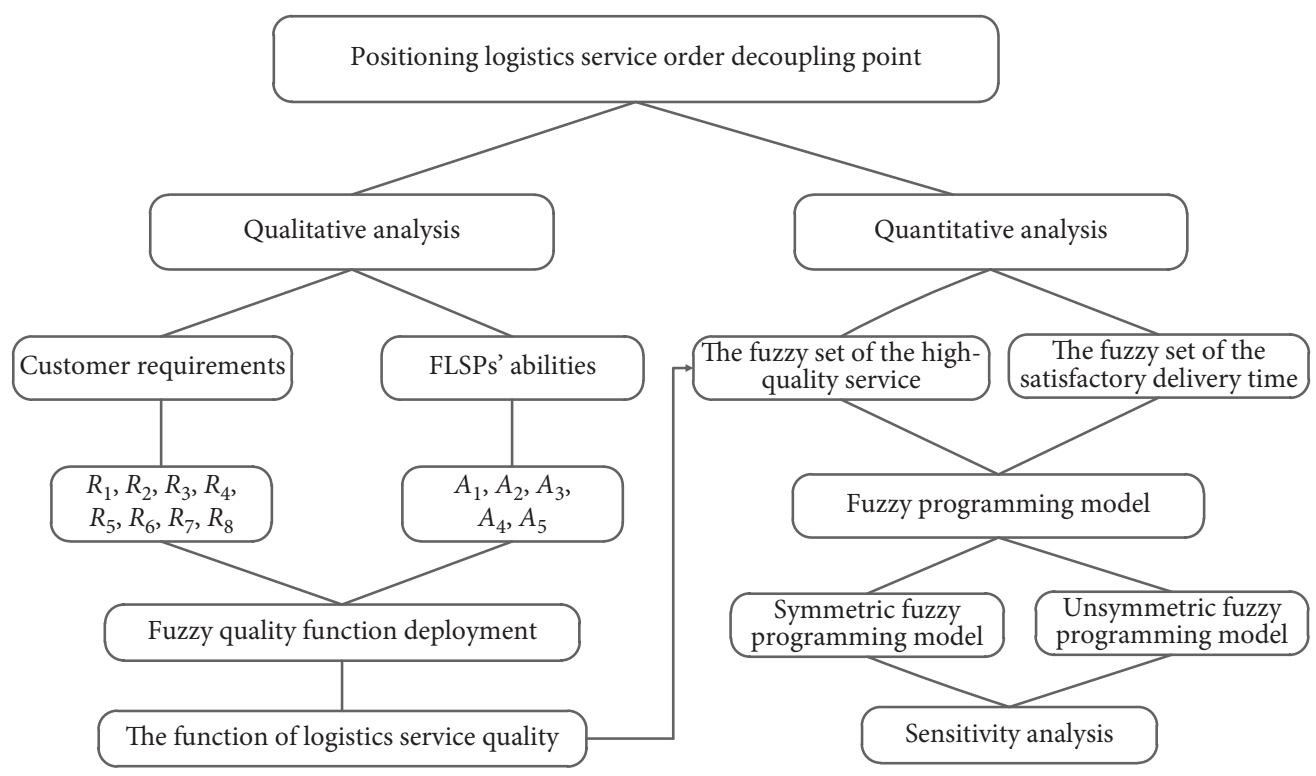

FIGURE 2: The proposed positioning CODP procedure.

TABle 2: Customer service quality factors: WHATs.

Service quality

requirements

Accuracy $\left(R_{1}\right)$

Organization accessibility

$\left(R_{2}\right)$

Flexibility $\left(R_{3}\right)$

Reliability $\left(R_{4}\right)$

Regularity $\left(R_{5}\right)$

Complaints management

$\left(R_{6}\right)$

Frequency $\left(R_{7}\right)$

Reasonable price $\left(R_{8}\right)$
Description

Avoidance of mistakes and damages in order delivered

Customer's opportunity to establish a contact with the LSI's staff

Capability to modify orders in terms of due date and quantity when required by customers Capability to deliver an order within the due date

The dispersion around the mean value of the delivered lead time

Process following the recognition of some errors in the service provided, which allows service quality standards to be re-established

Number of deliveries accomplished in a given time period

The acceptable price that customers are willing to pay (customer service quality requirements, i.e., service quality factors, "WHATs") and Table 3 (LSI service ability factors, "HOWs").

We obtained all of the above evaluating information by means of semistructured interviews [40], and then we use triangular fuzzy numbers to describe the information. For example, during the interview phase, there are $H$ customers to answer the questions about the importance of quality factors, another $L$ customers or experts to assess the degree of impact of the ability factor on the quality factor, and $M$ experts to evaluate the performance of the LSI service ability that selects CODPs with different positions; all of the evaluation information should be described by a 7 -point linguistic rating scale, ranging from VL (very low) to VH (very high). The fuzzy scale is shown in Table 4.The notations for Fuzzy QFD model are shown in Table 5.

According to the context, we build a house of quality, as shown in Figure 3. The next step is to develop the quantitative service quality index in terms of HOQ. The steps for this problem are as follows.
Step 1. Variable calculation.

First, we calculate the weight of the service quality factors according to the average method based on $H$ customers' evaluation information. Similarly, we use the average method to calculate the degree of impact of every ability factor on every quality factor. The formula for the calculation is as follows:

$$
\begin{aligned}
& \widetilde{\omega}_{i}=\frac{1}{H} \otimes \sum_{h=1}^{H} \widetilde{\omega}_{i h}, i=1, \ldots, I, \\
& \widetilde{e}_{i j}=\frac{1}{L} \otimes \sum_{l=1}^{L} \widetilde{e}_{i j l}, \quad i=1, \ldots, I ; j=1, \ldots, J .
\end{aligned}
$$

Step 2. Create matrixes.

The matrixes for the LS quality factor weight and capacity factor are created, respectively, as follows, based on the results of Step 1: 
TABLE 3: MC logistics service abilities: HOWs.

Service abilities

Information technology $\left(A_{1}\right)$

Process optimization capability

$\left(A_{2}\right)$

Logistics network service ability $\left(A_{3}\right)$

Facility integration capability

$\left(A_{4}\right)$

Emergency service capacity

$\left(A_{5}\right)$
Description

Sharing information in a timely manner, tracking logistics information, timely communication with customers, etc

The ability to integrate and optimize logistics business processes

The logistics network formed by different logistics nodes and logistics channels leading to different service abilities, which can be measured by the scale of the logistics network, coverage areas, etc

The capability to integrate facilities in logistics nodes and the logistics network

Ability to adjust to changes in consumer demand, emergency events, and incidents

TABLE 4: Linguistic judgments and corresponding fuzzy numbers.

\begin{tabular}{lr}
\hline Judgement & Triangular fuzzy number \\
\hline Very low & $(0,0,1.5)$ \\
Low & $(0,1.5,3)$ \\
Medium low & $(1.5,3,4.5)$ \\
Medium & $(3,4.5,6)$ \\
Medium high & $(4.5,6,7.5)$ \\
High & $(7.5,9,10)$ \\
Very high & $(9,10,10)$ \\
\hline
\end{tabular}

TABle 5: Notations for Fuzzy QFD model.

\begin{tabular}{|c|c|}
\hline Notations & Description \\
\hline$\overline{Q_{i}}$ & Logistics service quality index \\
\hline$\tilde{\omega}_{i}$ & Weight of $Q_{i}$ \\
\hline$\widetilde{\omega}_{i h}$ & The evaluation of the weight of the $i$ th service quality index by the $h$ th expert or customer \\
\hline$\tilde{c}_{j}$ & jth logistics services capability of the LSI \\
\hline E & Correlation matrix \\
\hline$\tilde{e}_{i j}$ & The impact of the $j$ th service capability on the $i$ th service quality \\
\hline$i^{i}$ & Serial number of the logistics service quality index \\
\hline$I$ & Numbers of logistics service quality indexes \\
\hline$j$ & Serial number of the logistics service technology and capacity index \\
\hline$J$ & Numbers of the logistics service technology and capacity indexes \\
\hline$H$ & The number of customers involved in evaluating the quality factor weights \\
\hline$L$ & The number of experts involved in the evaluation of the impact factors on quality factors \\
\hline$M$ & The number of experts involved in the evaluation of logistics services capabilities when selecting different CODPs \\
\hline$Y(k)$ & Comprehensive evaluation of service quality based on logistics service abilities \\
\hline$Q(Y)$ & The function of logistics service quality \\
\hline
\end{tabular}

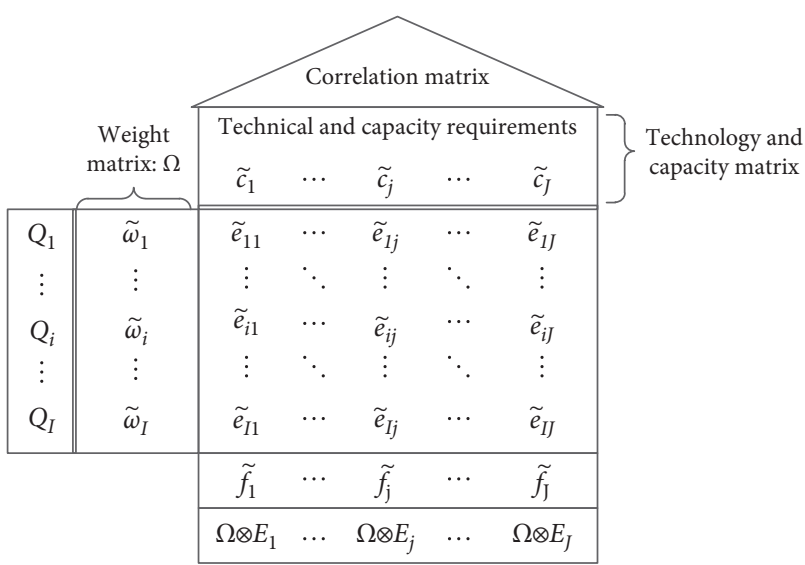

Figure 3: House of quality.

$$
\begin{aligned}
& \Omega=\left(\widetilde{\omega}_{1}, \ldots, \widetilde{\omega}_{i}, \ldots \widetilde{\omega}_{I}\right), \\
& C=\left(\widetilde{c}_{1}, \ldots, \widetilde{c}_{j}, \ldots, \widetilde{c}_{J}\right), \\
& E=\left(E_{1}, \ldots, E_{j}, \ldots, E_{J}\right)=\left(\begin{array}{ccccc}
\tilde{e}_{11} & \ldots & \tilde{e}_{1 j} & \ldots & \widetilde{e}_{1 J} \\
\vdots & \ddots & \vdots & \ddots & \vdots \\
\tilde{e}_{i 1} & \ldots & \tilde{e}_{i j} & \ldots & \widetilde{e}_{i J} \\
\vdots & \ddots & \vdots & \ddots & \vdots \\
\tilde{e}_{I 1} & \ldots & \tilde{e}_{I j} & \ldots & \tilde{e}_{I J}
\end{array}\right), \\
& E_{j}=\left(\widetilde{e}_{1 j}, \ldots, \widetilde{e}_{i j}, \ldots, \widetilde{e}_{I j}\right)^{\mathrm{T}} .
\end{aligned}
$$

Step 3. Matrix calculation. 
In this step, we need to calculate the influence degree of every ability factors on the overall service quality: $\widetilde{f}_{j}$, all the $\widetilde{f}_{j}$ constitute a matrix vector $F$ :

$$
\begin{aligned}
& \widetilde{f}_{j}=\frac{1}{I} \otimes \Omega \otimes E_{j}=\frac{1}{I} \otimes\left(\widetilde{\omega}_{1}, \ldots, \widetilde{\omega}_{i}, \ldots \widetilde{\omega}_{I}\right) \otimes\left(\widetilde{e}_{1 j}, \ldots, \widetilde{e}_{i j}, \ldots, \widetilde{e}_{I j}\right)^{\mathrm{T}}, \\
& F=\frac{1}{I} \otimes \Omega \otimes E=\left(\tilde{f}_{1}, \ldots, \tilde{f}_{j}, \ldots, \tilde{f}_{J}\right) .
\end{aligned}
$$

Step 4. Calculation of logistics service quality.

According to the above three steps, we know the influence degree of every ability factor on the overall service quality, so we can calculate the logistics service quality as long as we evaluate the LSI service ability under the condition that different CODPs are selected. Supposing there are $M$ logistics experts, $R_{j k m}$ is the evaluation for $j$ th logistics service ability by the $m$ th logistics expert when the CODP locates at $k$; then, we can calculate the overall evaluation for every logistics service ability when selecting different CODPs according to the average method based on $M$ experts evaluating information, $\widetilde{R}_{j k}$. The formula for the calculation is as follows:

$$
\widetilde{R}_{j k}=\frac{1}{M} \otimes \sum_{m=1}^{M} \widetilde{R}_{j k m}, \quad j=1, \ldots, J ; k=1, \ldots, N .
$$

Once $R_{j k}$ has been computed, the overall service quality can finally be determined as formulation (7). Since both $\widetilde{R}_{j k}$ and $\widetilde{f}_{j}$ are triangular fuzzy numbers, the results of their multiplication operations are also fuzzy numbers, so we convert those fuzzy numbers into real numbers to make the results more intuitive. Let $\widetilde{A}=(a, b, c)$ be a triangular fuzzy number, using the formulation $A=(a+2 b+c) / 4$ to convert $\widetilde{A}=(a, b, c)$ to an exact value:

$$
Y(k)=\frac{1}{J} \otimes \sum_{j=1}^{J}\left(\widetilde{R}_{j k} \otimes \widetilde{f}_{j}\right), \quad k=1, \ldots, N .
$$

When we chose different scoring standards, such as the centesimal system or the 10-point system, the results of formulation (7) will be different. To make results much easier to read and understand, we conduct a logistics service quality evaluating function as formulation (8). Obviously, the larger the value of the function, the higher the service quality is. More specifically, as the value of the function is closer to 1 than 0 , the service quality is increasingly improving. The logistics service quality evaluating function is shown as formulation (5):

$$
Q(Y)=\left(1+e^{-a \cdot(Y-b)}\right)^{-1}, \quad a>0, b>0 .
$$

In this function, the values of $a$ and $b$ depend on the value of $Y$, and the value of $Y$ is closely related to the scoring criteria. More specifically, when all of the evaluations for the abilities are the worst, we obtain the minimum value of $Y$ (denoted as $Y_{\min }$ ). Similarly, we obtain the maximum value of $Y$ (denoted as $Y_{\max }$ ) when all of the evaluations for the abilities are the best. Then, evenly map the interval number $\left[Y_{\min }, Y_{\max }\right]$ to $[0,1]$ through the service quality function. In formulation (8), we set $b=\left(Y_{\max }+Y_{\min }\right) / 2$, and the proper value of $a$ is calculated by an undetermined coefficient method.

4.2. Model Building. The objective function is to maximize total profit of the LSI when they implement the MC service mode. In this model, we use the difference between service price and total costs to indicate the profit of the LSI.

According to Assumption 4, we set the function of the degree of customization as

$$
D(k)=\frac{1}{1-N} \cdot k+\frac{N}{N-1}, \quad k=1, \ldots, N .
$$

Obviously, $1 / 1-N<0$, the degree of customization function is monotonically decreasing ink. $D(k)=1$, when $k=1 ; D(k)=0$, when $k=N ; 0<D(k)=N-k / N-1<1$, when $1<k<N$. Therefore, $D(k) \in[0,1]$.

According to Assumption 3, we set the service price function as

$$
P(k)=P_{s} \cdot\left[1+\frac{1}{N(1-\lambda)} D(k)\right], \quad k=1, \ldots, N .
$$

In formulation (10), $D(k)$ is the increased proportion of service price according to the degree of customization, $1 / 1-\lambda$ is the price compensation caused by sacrificing the scale effect, $1 / N$ is an adjustment coefficient designed to curb excessive price, and $P_{s}$ is the price of standardized service and the value of $P_{s}$ is decided by the LSI based on cost pricing. The formulation of $P_{s}$ is as follows:

$$
P_{s}=C(N) \cdot(1+r)=\sum_{i=1}^{N}(1-\lambda) c_{i} \cdot \mu \cdot(1+r) .
$$

Formula (10) means the higher the degree of customization is, the higher the price of LSI service is. When the customization levels tend to be 0 , the price of logistics service is close to $P_{s}$. In formula $(11), C(N)=\sum_{i=1}^{N}(1-\lambda) c_{i} \cdot \mu$ refers to the total cost for the LSI when the CODP is located at the last subprocedure; in other words, $C(N)$ is the cost that the LSI implements for a complete large-scale logistics service. $r$ is the target profit margin when the LSI provides mass service. Therefore, the objective function can be written as follows:

$$
\begin{aligned}
\max G(k)= & P(k)-C(k)=P_{s} \cdot\left[1+\frac{1}{N(1-\lambda)} D(k)\right] \\
& -\sum_{i=1}^{k}(1-\lambda) c_{i} \mu-\sum_{i=k+1}^{N} c_{i} \mu, \quad k=1, \ldots, N .
\end{aligned}
$$

To highlight the importance of lead time as well as reflect this new requirement for the time constraint, this paper separates lead time from other service evaluation indicators and sets it as an independent constraint condition. Therefore, there are two main constraints for this 
programming: the service quality constraint and the lead time constraint.

On the one hand, customers pursue high-quality service, which means the higher the service quality, the higher the customer satisfaction and loyalty; however, different positions of CODPs will lead to differentiated logistics service quality. We use a fuzzy set $\widetilde{A}(Q)$ to denote "High-quality of service;" its membership function is as formula (13), and its corresponding function curve is Figure 4. $\widetilde{A}(Q)$ is the possibility that the logistics service provided by the LSI is "high-quality service" when the decoupling point is located at $k$; it can also be understood as customer satisfaction with service quality when the CODP is located at the $k$ subprocedure:

$$
A(Q)= \begin{cases}0, & 0 \leq Q \leq 0.2, \\ \frac{(Q-0.6)^{2}}{0.32}, & 0.2 \leq Q<0.6, \\ 1-\frac{(Q-0.9)^{2}}{0.18}, & 0.6 \leq Q<0.9, \\ 1, & 0.9 \leq Q \leq 1 .\end{cases}
$$

On the other hand, the LSI's delivery time should be close to the customer's expected lead time. We use fuzzy set $\widetilde{B}$ to indicate this constraint, and the membership function of $\widetilde{B}$ can be described as formula (14). The graph of its membership function (it can also be understood as the time satisfaction function) is shown in Figure $5 . B(T)$ is the possibility that the LSI's lead time is close to the customer's expected lead time when the decoupling point is located at $k$ :

$$
B(T)= \begin{cases}{\left[1+\frac{\left(T(k)-T_{E}\right)^{2}}{T_{E}}\right]^{-1},} & T_{s} \leq T(k) \leq T_{l}, \\ 0, & T(k)<T_{s} \text { or } T(k)>T_{l} .\end{cases}
$$

Except the constraints mentioned above, $k$ should not be equal to 1 or $N$, since it means the LSI provides completely customized service, and when $k=1, k=N$ means the LSI provides completely standardized service, all of which are inconsistent with the background of our model.

To summarize, the CODP position model for a single service order is constructed as follows:

$$
\begin{aligned}
& \max G(k)=P(k)-C(k)={ }_{P s} \cdot\left(1+\frac{1}{N(1-\lambda)} D(k)\right)-\sum_{i=1}^{k}(1-\lambda)_{c i} \mu-\sum_{i=k+1}^{N}{ }_{i} \mu, \\
& \text { s.t. }\left\{\begin{array}{l}
Q(k) \in \widetilde{A}, \\
T(k) \in \widetilde{B}, \\
1<k<N .
\end{array}\right.
\end{aligned}
$$

4.3. Model Solution. Before solving the model, the relative importance of the objective function and constraints need to be defined first. For LSIs, if they regard maximizing profits and customer requirements (including quality requirements and delivery time requirements) as equally important, namely, the objective function and constraints are equally important; then, this model is a symmetric fuzzy programming model. If the LSI places more weight on maximizing profits, or conversely, they attach more importance to customer requirements, namely, the objective function and constraints are not equally important; then, the model is a unsymmetric fuzzy programming model. In this section, the solution of these two cases is given by referring to [41].

4.3.1. Symmetric Fuzzy Programming Model. The model is a symmetric fuzzy programming model when the LSI considers the objective function and constraints as equally important. Since $G(k)$ is a discrete function and $k$ is a finite integer, there must be a maximum $G(k)$ and a minimum $G(k)$. Therefore, we introduced a fuzzy set $M_{G}$ to solve the above fuzzy programming model, and its membership function can be written as follows:

$$
M_{G(k)}=\frac{G(k)-\min _{t \in N} G(t)}{\max _{t \in N} G(t)-\min _{t \in N} G(t)}, \quad k=1, \ldots, N
$$

Obviously, if $G$ reaches the maximum at $k^{1}, M_{G}\left(k^{1}\right)=1$. If $G$ obtains a minimum value at $k^{2}, M_{G}\left(k^{2}\right)=0$. If $G$ is neither maximum nor minimum at $k, \operatorname{MGk} \in(0,1)$. Therefore, $M_{G}(k)$ can be considered as the degree (or possibility) that $G(k)$ reaches the maximum at $k$, for $\forall k \in N^{*}$. In this view, the original model can be rewritten as 


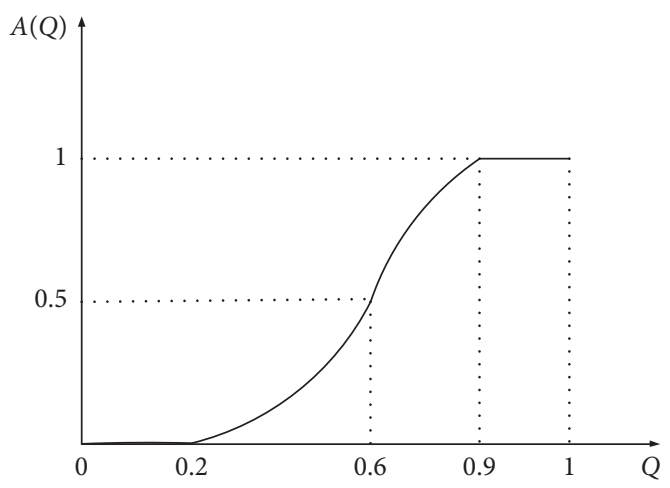

Figure 4: The membership function of fuzzy set $\widetilde{A}$.

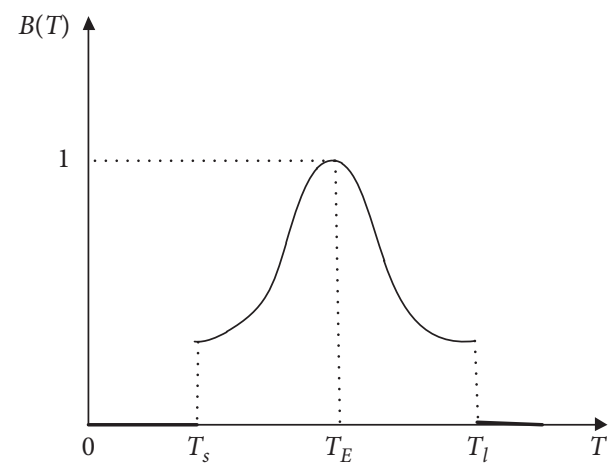

Figure 5: Fuzzy set B's membership function.

$$
\begin{aligned}
& \max y=M_{G}(k), \\
& \text { s.t. }\left\{\begin{array}{l}
Q(k) \in \widetilde{A}, \\
T(k) \in \widetilde{B}, \\
0<k<N .
\end{array}\right.
\end{aligned}
$$

Let $\widetilde{A}_{\alpha}, \widetilde{B}_{\beta}$ be the $\alpha$-cut set of $\widetilde{A}$ and the $\beta$-cut set of $\widetilde{B}$, respectively. Clearly, the process of finding the maximum of $G(k)$ on $\widetilde{A}_{\alpha}$ and $\widetilde{B}_{\beta}$ is equivalent to searching for the $k^{*}$ that meets the following condition:

$$
M_{G}\left(k^{*}\right)=\max _{k \in \widetilde{A}_{\alpha}, k \in \widetilde{B}_{\beta}} M_{G}(k) .
$$

Based on this, we transform model (17) into

$$
\begin{aligned}
& \max y=M_{G}(k), \\
& \text { s.t. }\left\{\begin{array}{l}
Q(k) \in \widetilde{A}_{\alpha}, \\
T(k) \in \widetilde{B}_{\beta}, \\
1<k<N .
\end{array}\right.
\end{aligned}
$$

Model (19) transforms the fuzzy constraints $A$ and $B$ into the deterministic constraints, and those deterministic constraints depend on the value of $\alpha-$ and $\beta-$. In other words, the solution of the above model must depend on the value of $\alpha$ and $\beta$.
A synthetic constraint fuzzy set is introduced to indicate all constraints. The expression of this synthetic constraint will change according to the preferences of different customers. Without loss of generosity, let $\alpha=\beta$, and the solution of model is recorded as $k(\alpha)$, and $k(\alpha)$ is a special $k$ that causes $G k$ to reach the maximum at the $\alpha$-level, where $\alpha \epsilon 0,1$ can be explained as the possibility (or guaranteeing rate) that $G(k)$ reaches the maximum under the fuzzy constrains:

$$
\begin{aligned}
\widetilde{S}(k) & =h(\widetilde{A}(k), \widetilde{B}(k))=\omega_{1} \otimes \widetilde{A}(k)+\omega_{2} \otimes \widetilde{B}(k), \\
0 & \leq \omega_{1}, \omega_{2} \leq 1, \omega_{1}+\omega_{2}=1 .
\end{aligned}
$$

To solve model (19), we first analyze the general property of $M_{G}(k)$ and give the definition of absolutely optimal level. Let $\alpha_{1}, \alpha_{2} \in(0,1]$ and $k\left(\alpha_{1}\right)$ and $k\left(\alpha_{2}\right)$ are the solutions of the model at the $\alpha 1$ and $\alpha 2$ level, respectively. Then,

$$
\alpha_{1}<\alpha_{2} \Longrightarrow S_{\alpha_{2}} \subseteq S_{\alpha_{1}} \Longrightarrow M_{G}\left(k\left(\alpha_{2}\right)\right) \leq M_{G}\left(k\left(\alpha_{1}\right)\right) \text {. }
$$

Formula (21) means $M_{G}(k(\alpha))$ is a nonincreasing function of $\alpha$.

Definition 1. If there exist a $\alpha^{*} \in(0,1)$, when $\alpha>\alpha^{*}$, $M_{G}\left(k\left(\alpha^{*}\right)\right)>M_{G}(k(\alpha))$, and when $0<\alpha<\alpha^{*}$, $M_{G}\left(k\left(\alpha^{*}\right)\right)=M_{G}(k(\alpha))$; then, $\alpha^{*}$ is described as the absolutely optimal level under the fuzzy constraint condition $\widetilde{S}(k)$, and its geometric description is shown as Figure 6 .

Since $M_{G}(k(\alpha))$ is a nonincreasing function of $\alpha$, $M_{G}(k(\alpha))>M_{G}(k(1))$ is always true for any $\alpha^{*} \in(0,1]$, namely, $M_{G}(k(\alpha)) \in\left[M_{G}(k(1)), M_{G}\left(k\left(\alpha^{*}\right)\right)\right], \forall \alpha \in(0,1]$. That means the possibility that $M_{G}=M_{G}(k(1))$ is 1 , but the value of $M_{G}(k(1))$ is relatively small. On the other hand, the possibility that $M_{G}=M_{G}\left(k\left(\alpha^{*}\right)\right)$ is $\alpha^{*}$, and it is impossible for MG to reach a value that is larger than $M_{G}\left(k\left(\alpha^{*}\right)\right)$, but $\alpha^{*} \in(0,1]$ is relatively small, which indicates that it is risky for the decision maker to get the maximal value (i.e., $M_{G}\left(k\left(\alpha^{*}\right)\right)$. Therefore, it is of great importance for the decision maker to choose an appropriate $\alpha^{*} \in(0,1]$, making $M_{G}$ reach a relatively satisfactory large value in the case of low risk.

According to the above analysis, we give the definition of the optimized point of the model.

Definition 2. Let constraint condition $\widetilde{S}(k)$ and objective $\widetilde{M}_{G}$ be the fuzzy sets in $N^{*}$, if

$$
M_{G}\left(k^{*}\right) \wedge S\left(k^{*}\right)=\max _{k \in N^{*}}\left(M_{G}(k) \wedge S(k)\right) .
$$

Then, we call $k^{*}$ the optimized point and call $G\left(k^{*}\right)$ the optimal value under the fuzzy constraint condition $\widetilde{S}(k)$, where $N^{*}$ is the universe of discourse.

4.3.2. Unsymmetric Fuzzy Programming Model. If the LSI pays different attention to the profit target and customer's request, it can express the different preference by setting different weight values to the objective function and the constraint condition, and the model is an unsymmetric fuzzy programming model. 


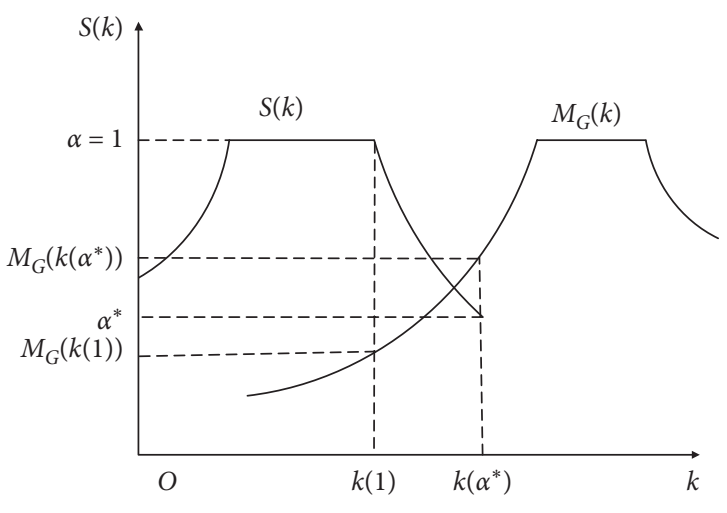

Figure 6: Absolutely optimal level.

Based on Section 4.3.1, introducing the fuzzy set $\widetilde{U}=\beta M_{G}+(1-\beta) \widetilde{S}, 0 \leq \beta \leq 1, \forall k \in N$, where $\beta$ is the weight of the objective function and $1-\beta$ is the weight of the constraint. The greater the $\beta$, the greater the LSI's attention to its short-term profit levels. Conversely, the LSI pays more attention to customer experience and customer satisfaction.

If $k^{*} \in N$, subjected to $\widetilde{U}\left(k^{*}\right)=\max _{k \in N} \widetilde{U}(k)$, then $k^{*}$ is the optimal point among $N$ and $G\left(k^{*}\right)$ is regarded as the best value.

\section{Numerical Study}

In this section, at first, the reliability of the model is proven through a numerical case; then, the effect on the outcome is observed when some parameters are changed by the sensitivity analysis. Finally, some important conclusions are obtained through the analysis of the results.

5.1. A Case Study. A LSI receives a logistics order from a customer enterprise, and the quantity of goods is $\mu=100$. After the analysis, it is found that the order can be divided into 8 service subprocedures. The LSI matches these subprocedures to the appropriate FLSPs. The unit operating cost of each subroutine $\left(c_{i}\right)$ and the operating time $\left(t_{i}\right)$ are shown in Table 6. The target profit margin is equal to 0.2 when the LSI provides standardized service, and the scale effect coefficient $(\lambda)$ is equal to 0.1 . The customer expectation delivery time is not less than 132 hours and is not more than 156 hours; the most suitable delivery time is 144 hours.

To enhance customer satisfaction, the LSI invited 5 customers to score the 8 service quality indicators mentioned above to determine the importance of those indicators, and three experts were asked to score the impact of the LSI's 5 logistics capabilities on the 8 services quality indicators. In addition, three experts were asked to score the logistics capabilities of the LSI when the LSI selected different CODPs, see Appendix for the specific scoring. Now, we need to determine a suitable decoupling point location to maximize the profit of the LSI as much as possible to meet the customer's requirements.
According to Table 6 and formulations (1), (2), and (12), we could calculate the total cost, total time, and gross profit when the LSI selects different CODPs. The results are shown in Table 7.

Based on the fuzzy QFD model and Appendix , we could obtain the score of the overall level of the logistics service quality. In this numerical case, we set the logistics service quality function as $Q(Y)=\left[1+e^{-0.02(Y-220)}\right]^{-1}$, and its function image is shown in Figure 7, and the results are shown in Table 8 .

From Table 8, we can clearly see that there are obvious differences in the logistics service quality when the LSI selects different CODPs. Among them, when $k=6$, the logistics service quality is the best. When $k=1$ or $k=2$, the logistics service quality is obviously poorer.

The membership function image of $\widetilde{A}$ and $\widetilde{B}$ are shown as Figures 8 and 9, respectively. According to Tables 7 and 8 and formulations (10) and (11), we could calculate the membership of $k^{*} \in \widetilde{A}, k^{*} \in \widetilde{B}$ when $k^{*}$ is equal to different value, respectively. Let the fuzzy set $\widetilde{S}(k)=0.5 \otimes \widetilde{A}+0.5 \otimes \widetilde{B}$ express synthetic constraints and calculate the membership of $\widetilde{S}$. According to Table 7 and formulation (16), we could calculate the membership of $k^{*} \in \tilde{M}_{G}$. All of the above calculation results are shown in Table 9.

Consider the first case, namely, finding the optimal CODP when the objective function and constraints are equally important. According to model (21), the results are shown in Table 10.

Based on Table 9 we know, when $M_{G}\left(k\left(\alpha^{*}\right)\right)=1$, the absolutely optimal level $\alpha^{*}$ is equal to 0.2446 under the synthetic constraint; in this case, $k\left(\alpha^{*}\right)=1$. In other words, when the profit reaches the maximum under the condition of the comprehensive fuzzy constraint, the position of the CODP is in the first subprocedure, but the guarantee rate is only 0.2446 . Because $k \neq 1$ and $k \neq N$, we can only choose the second largest $M_{G} \quad\left(M_{G}=0.867526\right)$; therefore, $\alpha^{*}=0.2551, k\left(\alpha^{*}\right)=2$.

Utilizing model (22),

$$
\begin{aligned}
M_{G}(k) \cap S= & \frac{0.2246}{k_{1}}+\frac{0.2551}{k_{2}}+\frac{0.607}{k_{3}}+\frac{0.55}{k_{4}} \\
& +\frac{0.3749}{k_{5}}+\frac{0.2488}{k_{6}}+\frac{0.1}{k_{7}}+\frac{0}{k_{8}}
\end{aligned}
$$

According to the maximum principle of membership degree, to maximize the profits of LSI in the case of comprehensive constraints, then we should select the 3rd subprocedure as the position of CODP, namely, $\alpha^{*}=0.607, k\left(\alpha^{*}\right)=3$.

From the above results, it is not difficult to find that when $k=3$, and the LSI can neither make the most profit nor maximize the customer satisfaction, but under the fuzzy programming model, the decision maker can make a tradeoff between the profit goal and customer satisfaction, namely, considering profit and customer satisfaction; we consider $k=3$ as the optimal decoupling point. 
TABLE 6: The unit cost and time of every service procedures.

\begin{tabular}{lcccccccc}
\hline$i$ & 1 & 2 & 3 & 4 & 5 & 6 & 7 & 8 \\
\hline Cost $\left(c_{i}\right)$ & 96 & 77 & 45 & 88 & 60 & 80 & 70 & 90 \\
Time $\left(t_{i}\right)$ & 19 & 13 & 15 & 15 & 18 & 16 & 14 & 17 \\
\hline
\end{tabular}

TABLe 7: Calculation results of total cost, total time, and gross profit.

\begin{tabular}{|c|c|c|c|c|c|c|c|c|}
\hline & $k=1$ & $k=2$ & $k=3$ & $k=4$ & $k=5$ & $k=6$ & $k=7$ & $k=8$ \\
\hline Total cost & 59640 & 58870 & 58420 & 57540 & 56940 & 56140 & 55440 & 54540 \\
\hline Total time & 129.1111 & 130.5556 & 132.2222 & 133.8889 & 135.8889 & 137.6667 & 139.2222 & 141.1111 \\
\hline Gross profit & 14898 & 14369.43 & 13520.86 & 13102.29 & 12403.71 & 11905.14 & 11306.57 & 10908 \\
\hline
\end{tabular}

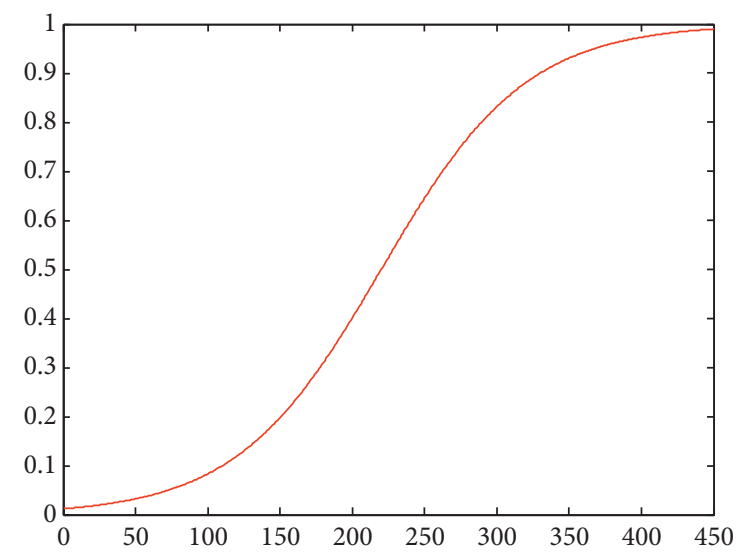

FIGURE 7: Logistics service quality function.

TABLE 8: Calculation results of logistics service quality.

\begin{tabular}{lccc}
\hline CODP & $\begin{array}{c}\text { Service quality described by fuzzy } \\
\text { numbers }\end{array}$ & $\begin{array}{c}\text { Service quality described by real } \\
\text { numbers }\end{array}$ & $\begin{array}{c}\text { The value of logistics quality function } \\
\text { service }\end{array}$ \\
\hline$k=1$ & $(116.96,235.64,376.22)$ & 241.12 & 0.5102 \\
$k=2$ & $(106.37,232.43,386.26)$ & 239.37 & 0.4892 \\
$k=3$ & $(109,240.87,435.29)$ & 256.51 & 0.7046 \\
$k=4$ & $(134.63,268.47,429.33)$ & 275.22 & 0.8768 \\
$k=5$ & $(141.32,267.72,427.21)$ & 279.7 & 0.9024 \\
$k=6$ & $(131.91,275.45,456.4)$ & 284.80 & 0.9267 \\
$k=7$ & $(138.41,266.72,415.11)$ & 271.74 & 0.8539 \\
$k=8$ & $(146.55,261.62,397.5)$ & 266.82 & 0.8166 \\
\hline
\end{tabular}

5.2. Sensitivity Analysis. In Section 5.1, we assume that the objective function and the constraint condition are equally important; in the following section, we discuss the change of the optimal decoupling point with the change of some parameters when the objective function and the constraints are unequally important. By observing the form of the objective function, we can see that when the position of the CODP moves downstream, both $P(k)$ and $C(k)$ are monotonically decreasing. If $P(k)$ decreased faster than $C(k)$ (denoted as the pricing strategy of 1 ), then the profit function $G(k)$ is monotonically decreasing, if $P(k)$ decreased slower than $C(k)$ (denoted as pricing strategy 2 ), then the profit function $G(k)$ is monotonically increasing. The impact of the scale effect coefficient and the objective function weight coefficient on the CODP position will be discussed in the following two cases.

5.2.1. Sensitivity Analysis of $\lambda$ and B under the Pricing Strategy of 1 . If we change the pricing function to $P(k)=$ $P_{s} \cdot[1+1 / 1-\lambda \cdot D(k)]$ to meet the requirements of pricing strategy 1 , the profit function is monotonically decreasing. Consider the first case, when the scale effect coefficient is equal to $0.2(\lambda=0.2)$, observing the impact of $\beta$ on the position of the CODP. Based on Section 4 and the data of Section 5.1, we observe the change of the CODP position when $\beta$ takes different values. The results are shown in Figure 10 . 


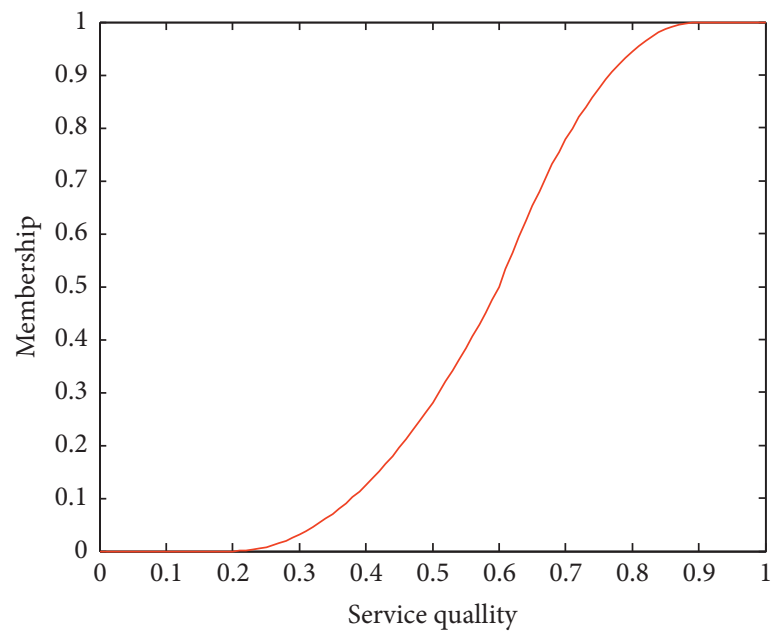

Figure 8: $A$ 's membership function.

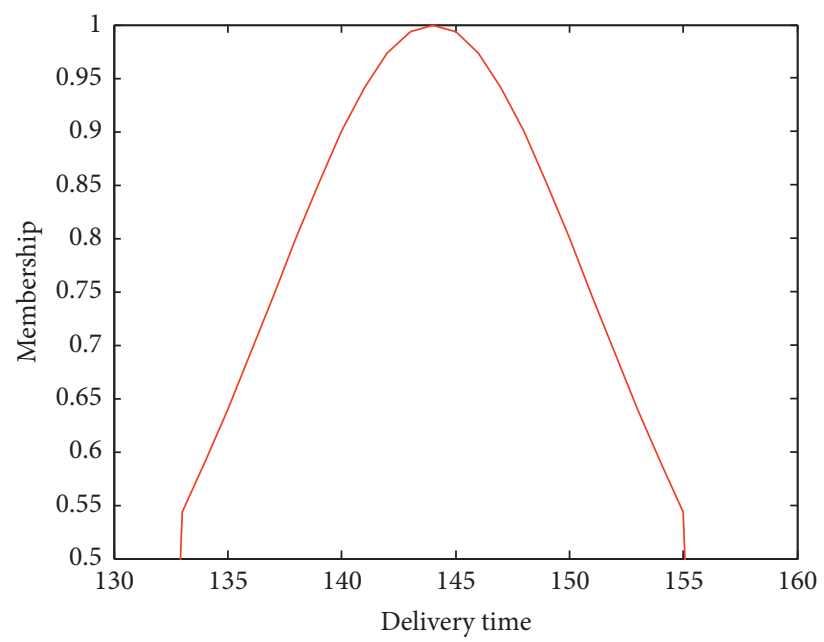

FIGURE 9: $\widetilde{B}$ 's membership function.

Table 9: The membership of $\widetilde{M}_{G}, \widetilde{A}, \widetilde{B}$, and $\widetilde{S}$.

\begin{tabular}{lcccccccc}
\hline$k$ & $k_{1}$ & $k_{2}$ & $k_{3}$ & $k_{4}$ & $k_{5}$ & $k_{6}$ & $k_{7}$ \\
\hline$\widetilde{M}_{G}$ & 1 & 0.867526 & 0.654851 & 0.549946 & 0.374866 & 0.24991 & 0.099893 \\
$\widetilde{A}$ & 0.4892 & 0.5102 & 0.7046 & 0.8768 & 0.9024 & 0.9267 & 0.8539 \\
$\widetilde{B}$ & 0 & 0 & 0.509345 & 0.584808 & 0.6864 & 0.782136 & 0.863169 & 0.8166 \\
$\widetilde{S}$ & 0.2446 & 0.2551 & 0.606972 & 0.730804 & 0.7944 & 0.854418 & 0.858534 & 0.88090909 \\
\hline
\end{tabular}

TABLe 10: Absolutely optimal level.

\begin{tabular}{lccc}
\hline$\alpha$ & $S_{\alpha}$ & $k(\alpha)$ & $M_{G}(k(\alpha))$ \\
\hline $0.8<\alpha \leq 1$ & $k_{6}, k_{7}, k_{8}$ & $k_{6}$ & 0.25 \\
$0.7<\alpha \leq 0.8$ & $k_{4}, k_{5}, k_{6}, k_{7}, k_{8}$ & $k_{4}$ & 055 \\
$0.6<\alpha \leq 0.7$ & $k_{3}, k_{4}, k_{5}, k_{6}, k_{7}, k_{8}$ & $k_{3}$ & 061 \\
$0.2<\alpha \leq 0.6$ & $k_{1}, k_{2}, k_{3}, k_{4}, k_{5}, k_{6}, k_{7}, k_{8}$ & $k_{1}$ & 1 \\
\hline
\end{tabular}




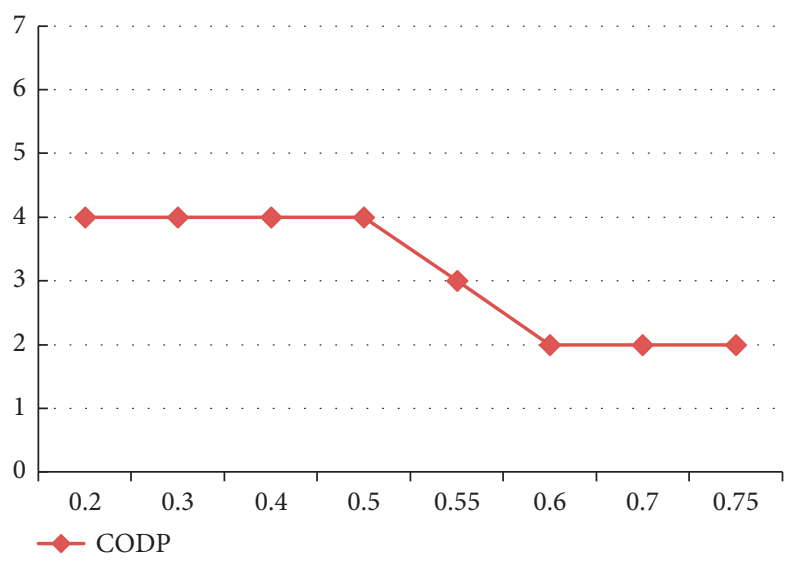

FIgure 10: Optimal CODP when different $\beta$ values are taken.

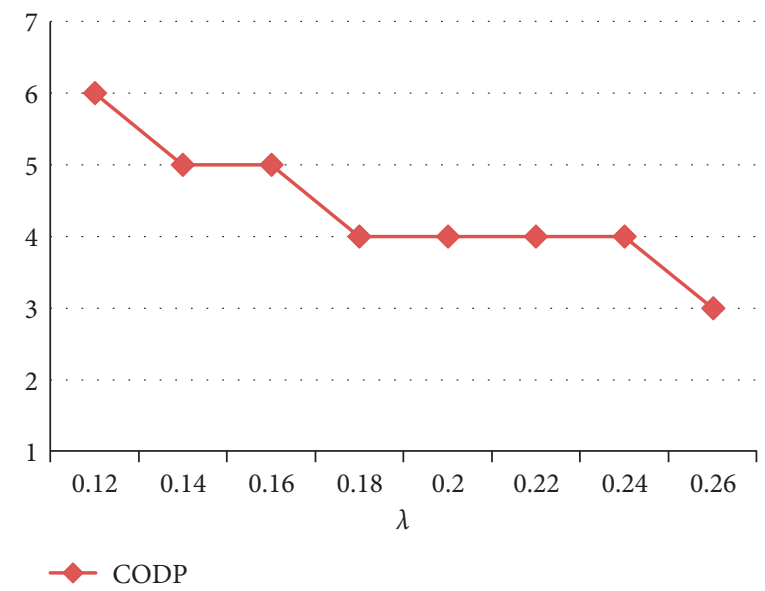

Figure 11: The optimal CODP when $\lambda$ changes from 0.12 to 0.26 .

As shown above, in this case, as the $\beta$ increases, the CODP moves upstream. This means that the LSI, in the pursuit of higher returns, will tend to ignore the needs of customers, which will enhance the level of LSI profits in the short term, but in the long term, poor quality of service or unsatisfactory delivery time will reduce customer satisfaction and affect the partnerships between the enterprise and the customers.

Considering the second case, namely, when $\beta$ is constant, we observe the change of the position of the optimal CODP caused by the change of $\lambda$. Since the value of $\beta$ will affect the LSI's decision, we observe the impact of $\lambda$ on the results when $\beta=0.3$ (i.e., the LSI focuses more on customer needs) and $\beta=0.7$ (i.e., LSI pays more attention to current earnings).

When $\beta=0.3$, the position change of the optimal CODP is recorded in the process of $\lambda$ rising from 0.12 to 0.26 . Using the numerical examples in Section 5.1, calculate the position of the CODP when $\lambda$ takes different values. The results are shown in Figure 11.

As shown in Figure 11, when $\beta=0.3$, the position of the optimal CODP will move upstream with the increase of $\lambda$. This occurs because the closer the decoupling point is to the downstream, the longer the delivery time, resulting in a decrease in time satisfaction. The bigger the $\lambda$, the faster the rate of time satisfaction drops, and thus, the CODP has the power to move upstream.

When $\beta=0.7$, to repeat the above steps and observe the position change of the CODP, we found that the optimal CODP is always located in the 2 nd subprocedure. In this case, the LSI pays more attention to its income level. Since the change of $\lambda$ will only change the size of earnings and will not change the variation trend of income, the LSI tends to locate the CODP in a higher income position. Figure 12 shows the change of LSI earnings in the process of CODP movement from upstream to downstream when the value of $\lambda$ is different.

5.2.2. Sensitivity Analysis of $\lambda$ and B under the Pricing Strategy of 2. If we change the pricing function to $P(k)=$ $P_{s} \cdot[1+1 / 16(1-\lambda) \cdot D(k)]$ to meet the requirements of pricing strategy 2 , the profit function is monotonically increasing, analysing the impact of $\lambda$ and $\beta$ on the position of the CODP. Similarly, we still divided it into two cases and 


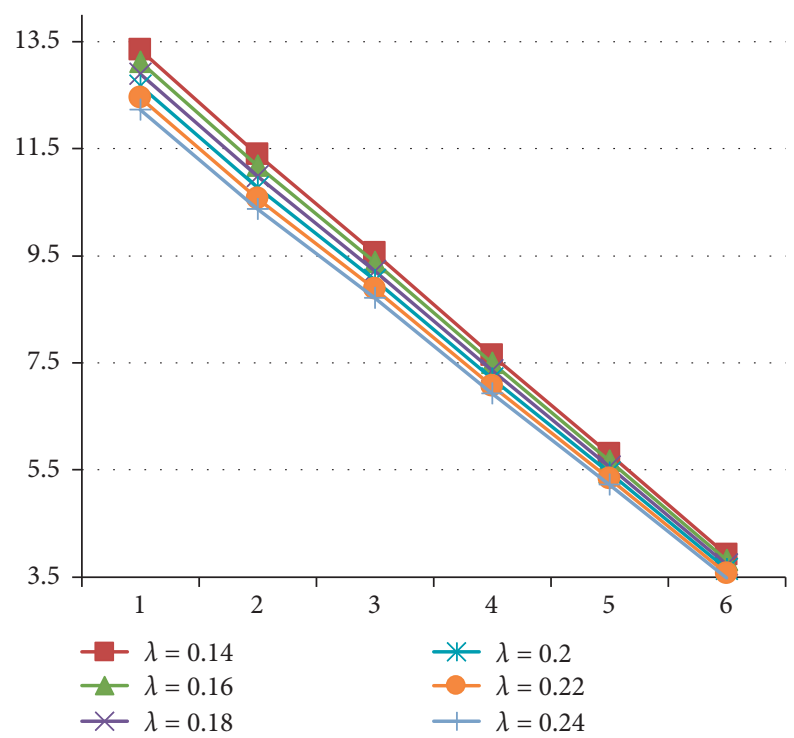

FIGURE 12: The LSI's profit when selecting different CODPs under the premise that $\lambda$ takes different values.

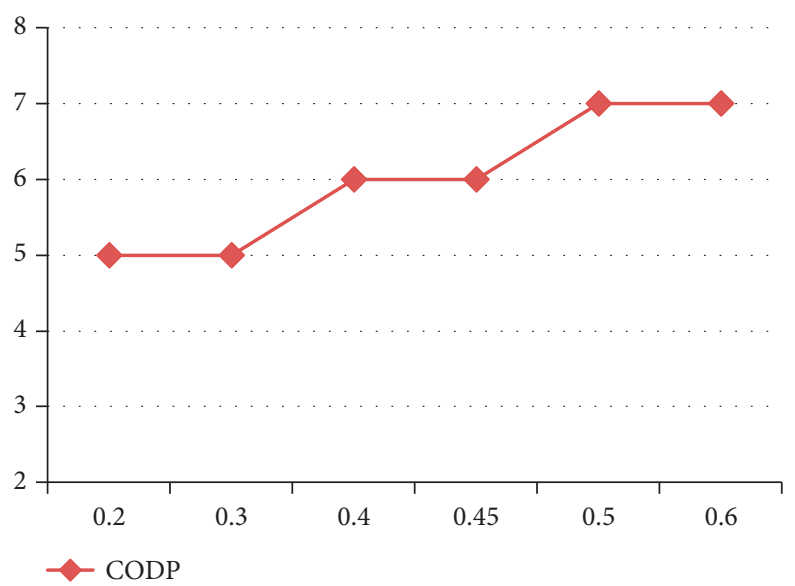

Figure 13: The optimal CODP when different $\beta$ values are taken under price strategy 2.

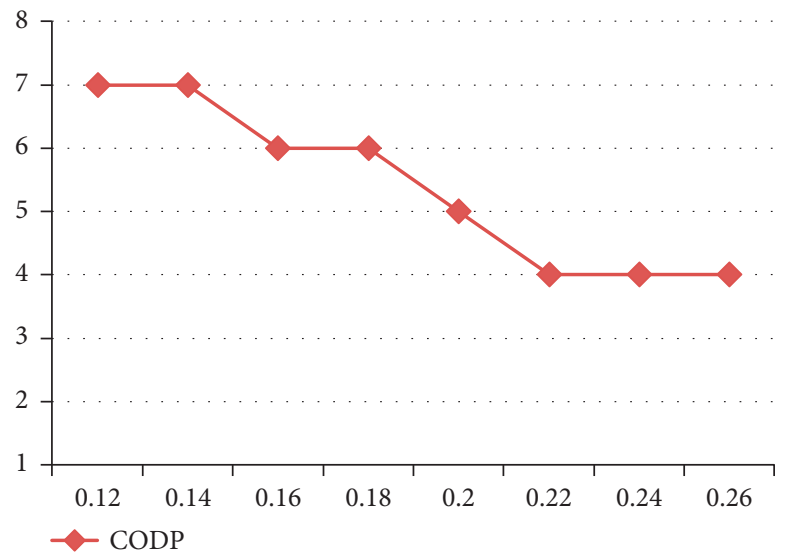

Figure 14: The optimal CODP when $\lambda$ changes from 0.12 to 0.26 . 
TABLE 11: Customer scoring information on the relative importance of the 8 service quality indicators.

\begin{tabular}{|c|c|c|c|c|c|c|c|c|c|}
\hline & & \multicolumn{8}{|c|}{ Service quality factors } \\
\hline & & Q1 & Q2 & Q3 & Q4 & Q5 & Q6 & Q7 & Q8 \\
\hline \multirow{5}{*}{$\begin{array}{l}\text { Importance } \\
\text { judgment by } \\
\text { linguistic rating } \\
\text { scale }\end{array}$} & $h 1$ & $\mathrm{H}$ & $\mathrm{VH}$ & $\mathrm{MH}$ & $\mathrm{H}$ & $\mathrm{MH}$ & $\mathrm{MH}$ & $\mathrm{H}$ & MH \\
\hline & $h 2$ & VH & $\mathrm{VH}$ & $\mathrm{H}$ & $\mathrm{MH}$ & $\mathrm{H}$ & $\mathrm{H}$ & $\mathrm{H}$ & $\mathrm{MH}$ \\
\hline & $h 3$ & $\mathrm{H}$ & $\mathrm{H}$ & $\mathrm{MH}$ & $\mathrm{H}$ & $\mathrm{MH}$ & $\mathrm{H}$ & $\mathrm{H}$ & $\mathrm{MH}$ \\
\hline & $h 4$ & VH & VH & $\mathrm{MH}$ & $\mathrm{H}$ & $\mathrm{MH}$ & VH & $\mathrm{H}$ & $\mathrm{H}$ \\
\hline & $h 5$ & $\mathrm{MH}$ & $\mathrm{MH}$ & $\mathrm{H}$ & $\mathrm{H}$ & $\mathrm{VH}$ & $\mathrm{MH}$ & $\mathrm{MH}$ & $\mathrm{H}$ \\
\hline \multirow{5}{*}{$\begin{array}{l}\text { Importance } \\
\text { described by fuzzy } \\
\text { numbers }\end{array}$} & $h 1$ & $(7.5,9,10)$ & $(9,10,10)$ & $(4.5,6,7.5)$ & $(7.5,9,10)$ & $(4.5,6,7.5)$ & $(4.5,6,7.5)$ & $(7.5,9,10)$ & $(4.5,6,7.5)$ \\
\hline & $h 2$ & $(9,10,10)$ & $(9,10,10)$ & $(7.5,9,10)$ & $(4.5,6,7.5)$ & $(7.5,9,10)$ & $(7.5,9,10)$ & $(7.5,9,10)$ & $(4.5,6,7.5)$ \\
\hline & $h 3$ & $(7.5,9,10)$ & $(7.5,9,10)$ & $(4.5,6,7.5)$ & $(7.5,9,10)$ & $(4.5,6,7.5)$ & $(7.5,9,10)$ & $(7.5,9,10)$ & $(4.5,6,7.5)$ \\
\hline & $h 4$ & $(9,10,10)$ & $(9,10,10)$ & $(4.5,6,7.5)$ & $(7.5,9,10)$ & $(4.5,6,7.5)$ & $(9,10,10)$ & $(7.5,9,10)$ & $(7.5,9,10)$ \\
\hline & $h 5$ & $(4.5,6,7.5)$ & $(4.5,6,7.5)$ & $(7.5,9,10)$ & $(7.5,9,10)$ & $(9,10,10)$ & $(4.5,6,7.5)$ & $(4.5,6,7.5)$ & $(7.5,9,10)$ \\
\hline $\begin{array}{l}\text { Relative } \\
\text { importance } \\
\text { of service quality } \\
\text { factors: } W_{i}\end{array}$ & & $(7.5,8.8,9.5)$ & $(7.8,9,9.5)$ & $(6,7.4,8.5)$ & $(7.2,8.6,9.5)$ & $(6,7.4,8.5)$ & $(6.6,8,9)$ & $(6.9,8.4,9.5)$ & $(5.7,7.2,8.5)$ \\
\hline
\end{tabular}

TABLE 12: The impact of various logistics service capabilities on different service quality indicators: scoring by the expert judgment method.

\begin{tabular}{|c|c|c|c|c|c|c|c|c|c|c|c|c|c|c|c|}
\hline & \multicolumn{3}{|c|}{$A_{1}$} & \multicolumn{3}{|c|}{$A_{2}$} & \multicolumn{3}{|c|}{$A_{3}$} & \multicolumn{3}{|c|}{$A_{4}$} & \multicolumn{3}{|c|}{$A_{5}$} \\
\hline & $C_{1}$ & $C_{2}$ & $C_{3}$ & $C_{1}$ & $C_{2}$ & $C_{3}$ & $C_{1}$ & $C_{2}$ & $C_{3}$ & $C_{1}$ & $C_{2}$ & $C_{3}$ & $C_{1}$ & $C_{2}$ & $C_{3}$ \\
\hline Q1 & $\mathrm{VH}$ & $\mathrm{H}$ & $\mathrm{H}$ & $M$ & $\mathrm{M}$ & $\mathrm{MH}$ & $\mathrm{M}$ & ML & $\mathrm{M}$ & $\mathrm{H}$ & $\mathrm{M}$ & $\mathrm{MH}$ & $\mathrm{ML}$ & $\mathrm{M}$ & $\mathrm{M}$ \\
\hline$Q_{2}$ & VH & $\mathrm{H}$ & $\mathrm{VH}$ & $\mathrm{MH}$ & $\mathrm{MH}$ & $\mathrm{M}$ & $\mathrm{L}$ & VL & $\mathrm{VL}$ & ML & VL & $\mathrm{L}$ & $\mathrm{L}$ & $\mathrm{L}$ & ML \\
\hline$Q_{3}$ & $\mathrm{MH}$ & $\mathrm{M}$ & $\mathrm{M}$ & $\mathrm{H}$ & $\mathrm{H}$ & $\mathrm{H}$ & $\mathrm{MH}$ & $\mathrm{H}$ & $\mathrm{H}$ & $\mathrm{M}$ & $\mathrm{M}$ & ML & $\mathrm{VH}$ & $\mathrm{VH}$ & $\mathrm{VH}$ \\
\hline$Q_{4}$ & $\mathrm{M}$ & $\mathrm{M}$ & $\mathrm{M}$ & VH & $\mathrm{H}$ & $\mathrm{VH}$ & $\mathrm{H}$ & $\mathrm{VH}$ & $\mathrm{MH}$ & $\mathrm{MH}$ & VH & $\mathrm{H}$ & $\mathrm{M}$ & ML & ML \\
\hline$Q_{5}$ & $\mathrm{H}$ & $\mathrm{H}$ & $\mathrm{MH}$ & $\mathrm{H}$ & $\mathrm{H}$ & $\mathrm{MH}$ & M & $\mathrm{M}$ & $\mathrm{M}$ & $\mathrm{M}$ & $\mathrm{M}$ & $\mathrm{MH}$ & ML & $\mathrm{M}$ & $\mathrm{M}$ \\
\hline$Q_{6}$ & $\mathrm{MH}$ & $\mathrm{MH}$ & $\mathrm{H}$ & ML & $\mathrm{L}$ & $\mathrm{L}$ & $\mathrm{L}$ & $\mathrm{ML}$ & ML & ML & VL & $\mathrm{L}$ & $\mathrm{ML}$ & $\mathrm{ML}$ & $\mathrm{L}$ \\
\hline$Q_{7}$ & $\mathrm{~L}$ & $\mathrm{~L}$ & ML & $\mathrm{MH}$ & $\mathrm{MH}$ & $\mathrm{H}$ & $\mathrm{H}$ & $\mathrm{MH}$ & $\mathrm{MH}$ & $\mathrm{MH}$ & $\mathrm{H}$ & $\mathrm{MH}$ & $\mathrm{MH}$ & $\mathrm{M}$ & $\mathrm{M}$ \\
\hline$Q_{8}$ & ML & $\mathrm{ML}$ & ML & $\mathrm{MH}$ & $\mathrm{H}$ & $\mathrm{MH}$ & $\mathrm{MH}$ & $\mathrm{MH}$ & $\mathrm{MH}$ & $\mathrm{VH}$ & $\mathrm{VH}$ & $\mathrm{H}$ & $\mathrm{VL}$ & $\mathrm{VL}$ & $\mathrm{L}$ \\
\hline
\end{tabular}

TABLE 13: The impact of various logistics service capabilities on different service quality indicators: described by fuzzy numbers.

\begin{tabular}{lccccc}
\hline & $A_{1}$ & $A_{2}$ & $A_{3}$ & $A_{4}$ & $A_{5}$ \\
\hline$Q_{1}$ & $(8.5,9.7,10)$ & $(3,4.5,6)$ & $(2.5,4,5.5)$ & $(5,6.5,7.8)$ & $(2.5,4,5.5)$ \\
$Q_{2}$ & $(8.5,9.7,10)$ & $(4,5.5,7)$ & $(0,0.5,2)$ & $(0.5,1.5,3)$ & $(0.5,1.5,3)$ \\
$Q_{3}$ & $(3.5,5,6.5)$ & $(7.5,9,10)$ & $(6,7.5,8.7)$ & $(2.5,4,5.5)$ & $(9,10,10)$ \\
$Q_{4}$ & $(3,4.5,6)$ & $(8.5,9.7,10)$ & $(7,8.3,9.2)$ & $(6,7.5,8.7)$ & $(2,3.5,5)$ \\
$Q_{5}$ & $(6.5,8,9.2)$ & $(6.5,8,9.2)$ & $(3,4.5,6)$ & $(0.5,1.5,3)$ & $(1,2.5,4)$ \\
$Q_{6}$ & $(5.5,7,8.3)$ & $(0.5,2,3.5)$ & $(5.5,7,8.3)$ & $(5.5,7,8.3)$ & $(3.5,5,6.5)$ \\
$Q_{7}$ & $(0.5,2,3.5)$ & $(3.5,5,6.5)$ & $(4.5,6,7.5)$ & $(8.5,9.7,10)$ & $(0,0.5,2)$ \\
$Q_{8}$ & $(1.5,3,4.5)$ & $(5.5,7,8.3)$ & & &
\end{tabular}

TABLE 14: The impact of different service capabilities on overall service quality.

\begin{tabular}{lcccc}
\hline$f_{1}$ & $f_{2}$ & $f_{3}$ & $f_{4}$ & $f_{5}$ \\
\hline$(32,50,66)$ & $(31,48,63)$ & $(24,40,58)$ & $(26,43,60)$ & $(17,32,47)$ \\
\hline
\end{tabular}

discussed them separately; the first case is observing the impact of $\beta$ on the position of the CODP when the scale effect coefficient is constant ( set $\lambda=0.2$ ).

As shown in Figure 13, when $\lambda=0.2$, the CODP moves downstream with the increasing of $\beta$. A greater $\beta$ means that the LSI is more concerned about the current level of income, and in this case, the level of earnings will increase as the decoupling points move downstream, so the movement of the CODP will show the trend in the graph above.
Consider the second case, namely, when $\beta$ is constant, observing the change of the optimal CODP position caused by the change of $\lambda$. Similarly, the value of $\beta$ will influence the LSI's decision. Therefore, we observe, respectively, the impact of $\lambda$ on the results when $\beta=0.3$ and $\beta=0.7$. When $\beta=0.3$, observing the change of the CODP position with $\lambda$ rising from 0.12 to 0.26 , the results are shown in Figure 14 .

As shown in Figure 14, when $\beta=0.3$, the CODP moved upstream with the increasing of $\lambda . \beta=0.3$ means that the LSI 
TABLE 15: LSI logistics service capability scoring information when decoupling points are in different positions: scoring by the expert judgment method.

\begin{tabular}{|c|c|c|c|c|c|c|c|c|c|c|c|c|c|c|c|}
\hline & \multicolumn{3}{|c|}{$A_{1}$} & \multicolumn{3}{|c|}{$A_{2}$} & \multicolumn{3}{|c|}{$A_{3}$} & \multicolumn{3}{|c|}{$A_{4}$} & \multicolumn{3}{|c|}{$A_{5}$} \\
\hline & $e_{1}$ & $e_{2}$ & $e_{3}$ & $e_{1}$ & $e_{2}$ & $e_{3}$ & $e_{1}$ & $e_{2}$ & $e_{3}$ & $e_{1}$ & $e_{2}$ & $e_{3}$ & $e_{1}$ & $e_{2}$ & $e_{3}$ \\
\hline$k=1$ & $\mathrm{VH}$ & $\mathrm{H}$ & $\mathrm{H}$ & $\mathrm{M}$ & $\mathrm{M}$ & $\mathrm{M}$ & $\mathrm{M}$ & $\mathrm{L}$ & $\mathrm{L}$ & VL & VL & $\mathrm{L}$ & $\mathrm{VH}$ & $\mathrm{VH}$ & VH \\
\hline$k=2$ & $\mathrm{H}$ & $\mathrm{H}$ & $\mathrm{VH}$ & ML & $\mathrm{L}$ & ML & ML & ML & $\mathrm{ML}$ & ML & VL & $\mathrm{L}$ & $\mathrm{H}$ & $\mathrm{H}$ & VH \\
\hline$k=3$ & $\mathrm{MH}$ & $\mathrm{MH}$ & $\mathrm{M}$ & $\mathrm{M}$ & $\mathrm{M}$ & $\mathrm{M}$ & $\mathrm{M}$ & $\mathrm{M}$ & $\mathrm{MH}$ & $\mathrm{MH}$ & $\mathrm{MH}$ & $\mathrm{M}$ & $\mathrm{MH}$ & $\mathrm{H}$ & $\mathrm{MH}$ \\
\hline$k=4$ & ML & ML & ML & $\mathrm{H}$ & $\mathrm{H}$ & MH & VH & $\mathrm{H}$ & $\mathrm{H}$ & $\mathrm{H}$ & $\mathrm{H}$ & $\mathrm{H}$ & ML & M & ML \\
\hline$k=5$ & $\mathrm{~L}$ & $\mathrm{~L}$ & $\mathrm{VL}$ & $\mathrm{VH}$ & $\mathrm{H}$ & $\mathrm{H}$ & $\mathrm{VH}$ & $\mathrm{VH}$ & $\mathrm{H}$ & $\mathrm{VH}$ & $\mathrm{H}$ & $\mathrm{H}$ & $\mathrm{VL}$ & ML & $\mathrm{L}$ \\
\hline$k=6$ & $\mathrm{M}$ & $\mathrm{M}$ & ML & $\mathrm{MH}$ & $\mathrm{H}$ & $\mathrm{H}$ & $\mathrm{MH}$ & $\mathrm{MH}$ & $\mathrm{MH}$ & $\mathrm{MH}$ & $\mathrm{VH}$ & $\mathrm{H}$ & $\mathrm{MH}$ & $\mathrm{H}$ & $\mathrm{MH}$ \\
\hline$k=7$ & $\mathrm{~L}$ & VL & $\mathrm{VL}$ & $\mathrm{VH}$ & $\mathrm{VH}$ & $\mathrm{H}$ & $\mathrm{VH}$ & $\mathrm{VH}$ & $\mathrm{H}$ & $\mathrm{VH}$ & $\mathrm{VH}$ & $\mathrm{H}$ & $\mathrm{VL}$ & $\mathrm{L}$ & $\mathrm{L}$ \\
\hline$k=8$ & VL & VL & VL & $\mathrm{VH}$ & $\mathrm{VH}$ & VH & VH & $\mathrm{VH}$ & $\mathrm{VH}$ & $\mathrm{VH}$ & $\mathrm{VH}$ & VH & VL & VL & VL \\
\hline
\end{tabular}

TABLE 16: LSI logistics service capability scoring information when decoupling points are in different positions: described by fuzzy numbers.

\begin{tabular}{|c|c|c|c|c|c|}
\hline & $A_{1}$ & $A_{2}$ & $A_{3}$ & $A_{4}$ & $A_{5}$ \\
\hline$k=1$ & $(8.5,9.7,10)$ & $(3,4.5,6)$ & $(0,1.5,3)$ & $(0,0,1.5)$ & $(9,10,10)$ \\
\hline$k=2$ & $(8,9.3,10)$ & $(1,2.5,4)$ & $(1.5,3,4.5)$ & $(0.5,2,3.5)$ & $(8,9.3,10)$ \\
\hline$k=3$ & $(4,5.5,7)$ & $(3,4,5.6)$ & $(3.5,5,6.5)$ & $(4,5.5,7)$ & $(5.5,7,8.3)$ \\
\hline$k=4$ & $(1.5,3,4.5)$ & $(6,7.5,8.7)$ & $(8,9.3,10)$ & $(7.5,7.5,7.5)$ & $(2,3.5,5)$ \\
\hline$k=5$ & $(0,1,2.5)$ & $(9,10,10)$ & $(8.5,9.7,10)$ & $(8,9.3,10)$ & $(0.5,1.5,3)$ \\
\hline$k=6$ & $(2.5,4,5.5)$ & $(6.5,8,9.17)$ & $(4.5,6,7.5)$ & $(7.5,8.3,9.2)$ & $(3.5,5,6.5)$ \\
\hline$k=7$ & $(0,0.5,2)$ & $(8.5,9.7,10)$ & $(8.5,9.7,10)$ & $(8.5,9.7,10)$ & $(0,1,2.5)$ \\
\hline$k=8$ & $(0,0,1.5)$ & $(9,10,10)$ & $(9,10,10)$ & $(9,10,10)$ & $(0,0,1.5)$ \\
\hline
\end{tabular}

pays great attention to the customer's quality of service and delivery time $(1-\beta=0.7)$. The lead time will increase with the rising of $\lambda$. To make the delivery time more in line with the customer's requirements, the LSI has to sacrifice shortterm earnings to maintain customer relationships so that CODP moves upstream.

When $\beta=0.7$, the optimal CODP always locates in the 7 th subprocedure for any value of $\lambda$ in interval $[0.12,026]$. $\beta=0.7$ means that LSI attaches great importance to the current income, while it ignores the needs of the customer enterprises. Under the price strategy of 2 , the earning level of the LSI will gradually increase as the CODP moves from upstream to downstream, and the variation of $\lambda$ will only affect the value of earnings but will not change the trend.

\section{Conclusions}

This paper constructs a fuzzy programming model based on the fuzzy set of the high-quality service and the fuzzy set of the satisfactory delivery time by means of combination of qualitative analysis and quantitative analysis. Compared with traditional deterministic programming models, we consider the ambiguity of the requirements for service quality and delivery time and use the fuzzy set theory to describe the fuzziness, which makes the model closer to the real situation. Under this model, decision makers can consider more indicators to measure the logistics service quality, and at the same time, the decision-making process is more flexible, which can better reflect the subjective preferences of decision makers. The CODP positioning method designed in this paper is helpful to the continuous improvement of service quality and sustainable development of the logistics service supply chain.
The research of this paper provides some useful perspectives for enterprise managers who provide logistics services. First, the scale effect coefficient has a significant effect on the position of the optimal CODP. Therefore, enterprise managers should increase the scale effect as much as possible within the scope of logistics service capabilities, such as expanding the scope of services to obtain more logistics orders, improving standardized operation capabilities, strengthening staff training on standardized operation procedures, and scientifically using order delay strategies to gather similar services types of orders.

Second, it is difficult to find a CODP that can maximize the LSI profits and the customer satisfaction at the same time. Therefore, business managers need to make a trade-off during decision-making and decide if they are willing to improve the short-term income level and ignore customer satisfaction or maintain long-term cooperation with customers at the expense of part of the proceeds.

Both the operation time of the mass service and the operation time of the customized service are assumed to be definite in this paper, and in reality, there often exist some fluctuation in the operation time. Therefore, a possible extension of the study includes considering the CODP positioning problem in the case of fuzzy operation time of the FLSPs.

\section{Appendix}

According to the scoring information of customers and experts for different indicators (as shown in Tables 11 13), we calculate the impact of different service capabilities on overall service quality based on Section 4.2. procedures (the calculation results are shown in Table 14). According to the scoring 
information of experts for LSI's service abilities when selecting different CODP (scoring information are shown in Tables 15 and 16), combining the data of Table 14, we can calculate the value of logistics service quality under different decoupling points, and the results are shown in Table 8.

\section{Data Availability}

Data can be available upon request to the corresponding author.

\section{Conflicts of Interest}

The authors declare that they have no conflicts of interest.

\section{Acknowledgments}

This research was supported by Ministry of Education Humanities and Social Sciences Research Project of China (16YJA630017) and Open Research Fund Program of Key Laboratory of Process Optimization and Intelligent Decision-making (Hefei University of Technology), Ministry of Education.

\section{References}

[1] Q. Zhao, H. Ding, and H. Liu, "Logistics service process reengineering for mass customization," in Proceedings of the IEEE International Conference on Services Systems and Services Management, pp. 369-374, Chongquing, China, June 2005.

[2] W. Liu, H. Xu, X. Sun, Y. Yang, and Y. Mo, "Order allocation research of logistics service supply chain with mass customization logistics service," Mathematical Problems in Engineering, vol. 2013, Article ID 957260, 13 pages, 2013.

[3] C. Wang and F. Dargahi, "Service customization under capacity constraints: an auction-based model," Journal of Intelligent Manufacturing, vol. 24, no. 5, pp. 1033-1045, 2012.

[4] F. S. Fogliatto, G. J. C. Da Silveira, and R. Royer, "Flexibilitydriven index for measuring mass customization feasibility on industrialized products," International Journal of Production Research, vol. 41, no. 8, pp. 1811-1829, 2003.

[5] B. Joseph Pine and A. C. Boynton, Making Mass Customization Work, pp. 109-116, Harvard Business Review, Brighton, MA, USA, 1993.

[6] W. Liu, Y. Yang, H. Xu, X. Liu, Y. Wang, and Z. Liang, “A time scheduling model of logistics service supply chain based on the customer order decoupling point: a perspective from the constant service operation time," The Scientific World Journal, vol. 2014, Article ID 756178, 22 pages, 2014.

[7] J. Olhager, "The role of the customer order decoupling point in production and supply chain management," Computers in Industry, vol. 61, no. 9, pp. 863-868, 2010.

[8] J. Olhager, "Strategic positioning of the order penetration point," International Journal of Production Economics, vol. 85, no. 3, pp. 319-329, 2003.

[9] M. Rudberg and J. Wikner, "Mass customization in terms of the customer order decoupling point," Production Planning \& Control, vol. 15, no. 4, pp. 445-458, 2004.

[10] J. Wikner, "A service decoupling point framework for logistics, manufacturing, and service operations," International Journal of Services Sciences, vol. 4, no. 3/4, pp. 330-357, 2012.
[11] W. Liu, R. Wu, Z. Liang, and D. Zhu, "Decision model for the customer order decoupling point considering order insertion scheduling with capacity and time constraints in logistics service supply chain," Applied Mathematical Modelling, vol. 54, pp. 112-135, 2018.

[12] W. Liu, X. Shen, and D. Xie, "Decision method for the optimal number of logistics service providers with service quality guarantee and revenue fairness," Applied Mathematical Modelling, vol. 48, pp. 53-69, 2017.

[13] W. Liu, Z. Liang, Z. Ye, and L. Liu, "The optimal decision of customer order decoupling point for order insertion scheduling in logistics service supply chain," International Journal of Production Economics, vol. 175, pp. 50-60, 2016.

[14] A. K. Rahmat and N. Faisol, "Manufacturers satisfaction on logistics service quality: operational, relational and national culture," Procedia-Social and Behavioral Sciences, vol. 224, pp. 339-346, 2016.

[15] S. Limbourg, H. T. Q. Giang, and M. Cools, "Logistics service quality: the case of Da Nang City," Procedia Engineering, vol. 142, pp. 124-130, 2016.

[16] I. Meiduté-Kavaliauskienè, A. Aranskis, and M. Litvinenko, "Consumer satisfaction with the quality of logistics services," Procedia-Social and Behavioral Sciences, vol. 110, pp. 330-340, 2014.

[17] F. Franceschini and C. Rafele, "Quality evaluation in logistic services," International Journal of Agile Management Systems, vol. 2, no. 1, pp. 49-54, 2000.

[18] L. M. R. R. A. Novack and C. John Langley Jr., "An internal assessment of logistics value," Journal of Business Logistics, vol. 15, pp. 113-152, 1994.

[19] J. T. Mentzer, "Developing a logistics service quality scale," Journal of Business Logistics, vol. 20, no. 1, pp. 1-7, 1999.

[20] X. Y. Sun, P. Ji, L. Y. Sun, and Y. L. Wang, "Positioning multiple decoupling points in a supply network," International Journal of Production Economics, vol. 113, no. 2, pp. 943-956, 2008.

[21] Y. Wang and Y. Chen, "Multi-CODP adjustment model and algorithm driven by customer requirements in dynamic environments," Cluster Computing, vol. 19, no. 4, pp. 2119-2131, 2016.

[22] J.-h. Ji, L.-l. Qi, and Q.-1. Gu, "Study on CODP position of process industry implemented mass customization," Systems Engineering-Theory \& Practice, vol. 27, no. 12, pp. 151-157, 2007.

[23] F. S. Fogliatto, G. J. C. da Silveira, and D. Borenstein, "The mass customization decade: an updated review of the literature," International Journal of Production Economics, vol. 138, no. 1, pp. 14-25, 2012.

[24] S. K. Moon, J. Shu, T. W. Simpson, and S. R. T. Kumara, “A module-based service model for mass customization: service family design," IIE Transactions, vol. 43, no. 3, pp. 153-163, 2010.

[25] Z. Wang, X. Xu, and X. Wang, "Mass customization oriented and cost-effective service network," Lecture Notes in Business Information Processing, vol. 144, pp. 172-185, 2013.

[26] L. Peters and H. Saidin, "IT and the mass customization of service: the challenge of implementation," International Journal of Information Management, vol. 20, pp. 103-119, 2000.

[27] X. Hu, G. Wang, X. Li, Y. Zhang, S. Feng, and A. Yang, "Joint decision model of supplier selection and order allocation for the mass customization of logistics services," Transportation Research Part E: Logistics and Transportation Review, vol. 120, pp. 76-95, 2018. 
[28] G. Wang, X. Hu, X. Li, Y. Zhang, S. Feng, and A. Yang, "Multiobjective decisions for provider selection and order allocation considering the position of the CODP in a logistics service supply chain," Computers \& Industrial Engineering, vol. 140, 2020.

[29] I.-J. Jeong, "A dynamic model for the optimization of decoupling point and production planning in a supply chain," International Journal of Production Economics, vol. 131, no. 2, pp. 561-567, 2011.

[30] M. Schoenwitz, A. Potter, J. Gosling, and M. Naim, "Product, process and customer preference alignment in prefabricated house building," International Journal of Production Economics, vol. 183, pp. 79-90, 2017.

[31] M. de Keizer, R. Akkerman, M. Grunow, J. M. Bloemhof, R. Haijema, and J. G. A. J. van der Vorst, "Logistics network design for perishable products with heterogeneous quality decay," European Journal of Operational Research, vol. 262, no. 2, pp. 535-549, 2017.

[32] H. Shidpour, C. Da Cunha, and A. Bernard, "Analyzing single and multiple customer order decoupling point positioning based on customer value: a multi-objective approach," Procedia CIRP, vol. 17, pp. 669-674, 2014.

[33] V. G. Cannas, J. Gosling, M. Pero, and T. Rossic, “Engineering and production decoupling configurations: an empirical study in the machinery industry," International Journal of Production Economics, vol. 216, pp. 173-189, 2019.

[34] L. C. Guo, Suhao, J. K. Allen, and F. Mistree, "Designing the customer order decoupling point to facilitate mass customization," in Proceedings of the ASME International Design Engineering Technical Conferences/Computers and Information in Engineering Conference AMER SOC Mechanical Engineers, Anaheim, CA, USA, August 2020.

[35] W. Liu, Q. Wang, D. Zhu, and Y. Liu, "A determination method of optimal customization degree of logistics service supply chain with mass customization service," Discrete Dynamics in Nature and Society, vol. 2014, Article ID 212574, 14 pages, 2014.

[36] C. Babbar and S. H. Amin, "A multi-objective mathematical model integrating environmental concerns for supplier selection and order allocation based on fuzzy QFD in beverages industry," Expert Systems with Applications, vol. 92, pp. 27-38, 2018.

[37] H. Akbaş and B. Bilgen, "An integrated fuzzy QFD and TOPSIS methodology for choosing the ideal gas fuel at WWTPs," Energy, vol. 125, pp. 484-497, 2017.

[38] C. K. M. Lee, C. T. Y. Ru, C. L. Yeung, K. L. Choy, and W. H. Ip, "Analyze the healthcare service requirement using fuzzy QFD," Computers in Industry, vol. 74, pp. 1-15, 2015.

[39] C.-N. Liao and H.-P. Kao, "An evaluation approach to logistics service using fuzzy theory, quality function development and goal programming," Computers \& Industrial Engineering, vol. 68, pp. 54-64, 2014.

[40] Y. Lin, S. Pekkarinen, and S. Pekkarinen, "QFD-based modular logistics service design," Journal of Business \& Industrial Marketing, vol. 26, no. 5, pp. 344-356, 2011.

[41] B. Hu, Foundations of Fuzzy Theory, Wuhan University Press, Wuhan, China, 2010. 